\title{
Transfer of Air Force Technical Procurement Bid Set Data to Small Businesses, Using CALS and EDI
}

\author{
Summary Report
}

10 January 1995

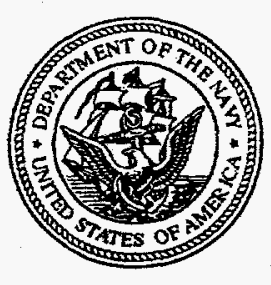

Prepared by

Lawrence Livermore National Laboratory

\section{Prepared for}

Electronic Systems Center

Air Force CALS Program Office

HQ ESC/AV-2

4027 Colonel Glenn Hwy Suite 300

Dayton OH 45431-1672 


\section{DISCLAIMERS}

This document was prepared as an account of work sponsored by an agency of the United States Government. Neither the United States Government nor the University of California nor any of their employees makes any warranty, express or implied, or assumes any legal liability or responsibility for the accuracy, completeness, or usefulness of any information, apparatus, product, or process disclosed, or represents that its use would not infringe privately owned rights. Reference herein to any specific commercial product, process, or service by trade name, trademark, manufacturer, or otherwise, does not necessarily constitute or imply its endorsement, recommendation, or favoring by the United States Government or the University of California. The views and opinions of authors expressed herein do not necessarily state or reflect those of the United States Government or the University of California, and shall not be used for advertising or product endorsement purposes.

This report has been reproduced directly from the best available copy.

Available to DOE and DOE contractors from the Office of Scientific and Technical Information

P.O. Box 62, Oak Ridge, TN 37831-9939

Prices available from (615) 576-8401

Available to the public from the

National Technical Information Service

U.S. Department of Commerce

5285 Port Royal Rd,

Springfield, VA 22161

\section{TRADEMARKS}

Trademarks: Advantis: Advantis; Expedite, MVS, PCX, PS2, XT: International Business Machine Corp.; AOS, MV9500: Data General Corp.; Arenet: DataPoint Corp.; Datatran: St. Paul Software; Datatrek 12/2400 Modem: Datatrek; Ethernet: Xerox Corp.; Easylink, Global Messaging Service, Merlin, UNIX: AT\&T; HiJaak: Inset Systems Inc.; IPL: IPL Systems, Inc.; MacEDI: Digit Software; Macintosh: Apple Computer, Inc.; [80]286, [80]386, [80]486: Intel Corp.; MS-DOS, Paintbrush for Windows: Microsoft Corp.; Myriad: Informative Graphics, Inc.; MultiTech: Multi-Tech Systems Inc; RFS Software: Radio Frequency System, Inc.; SPARC, SPARCstation IPC, SunOS: Sun Microsystems, Inc.; STX, STX12: Supply Tech, Inc.; Smartmodem, Ultra Smartmodem: Hayes Microcomputer Products; Wollongong WIN3B: Wollongong Group; WordPerfect: WordPerfect Corp.; ZM-2401 Modem: Zenith Radio Corp.

All references to brands or trademarks are the property of their respective owners. The recognition of these products does not constitute recommendation or endorsement.

This report and the Air Force CALS Test Network do not endorse any product, process, or company. The use of a particular vendor product does not imply "CALS compatibility, compliance, conformance, or certification." Therefore, the AFCTN will not endorse or recommend specific vendor products.

Work performed under the auspices of the U.S. Department of Energy by Lawrence Livermore National Laboratory under Contract W-7405-Eng-48. 


\section{DISCLAIMER}

Portions of this document may be illegible in electronic image products. Images are produced from the best available original document. 


\section{Contents}

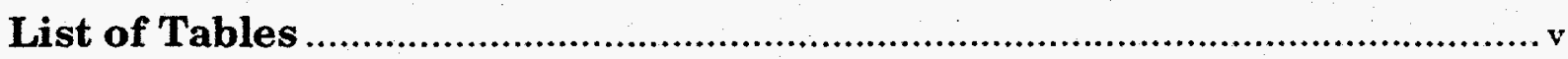

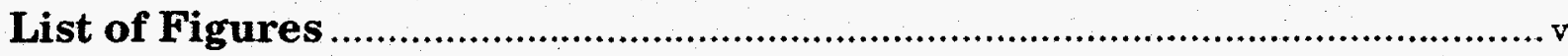

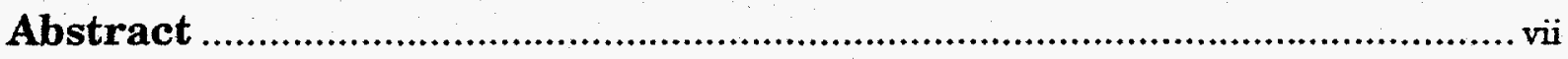

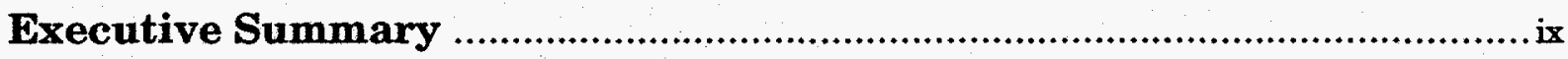

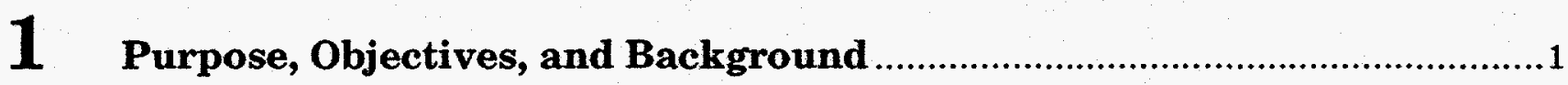

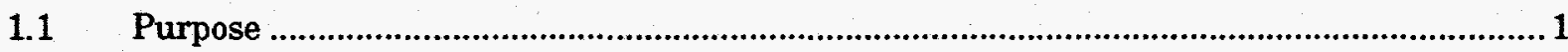

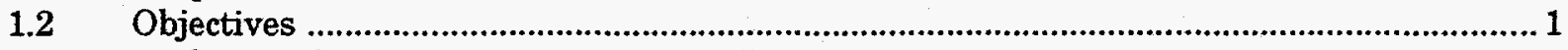

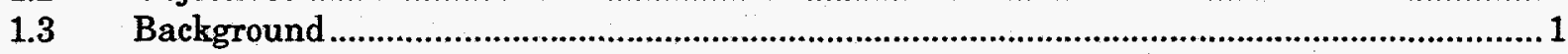

1.3.1 Summary of Air Force CALS Test Network CALS-EDI Testing................................ 1

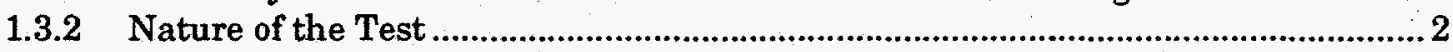

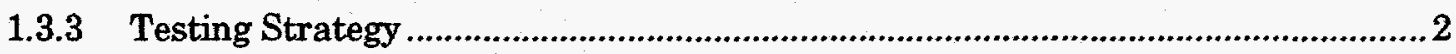

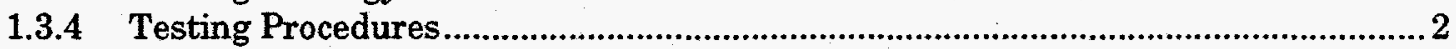

1.3.5 Standards and Specifications Tested .......................................................................

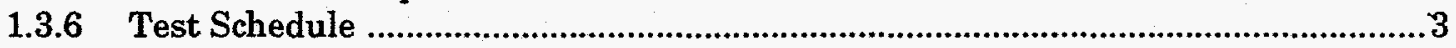

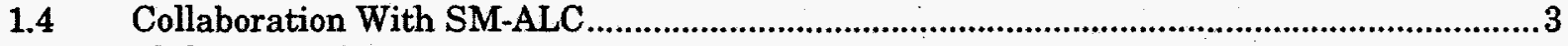

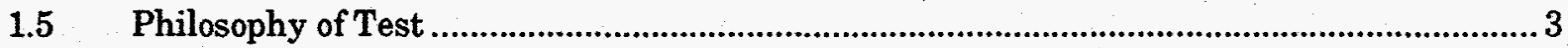

$1.6 \quad$ Use of COTS Hardware and Software ................................................................................ 3

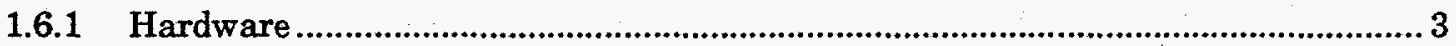

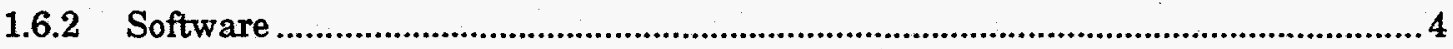

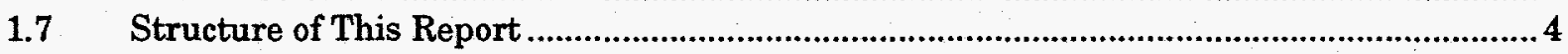

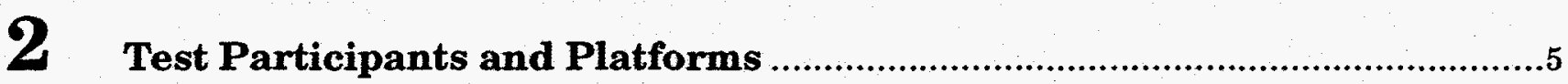

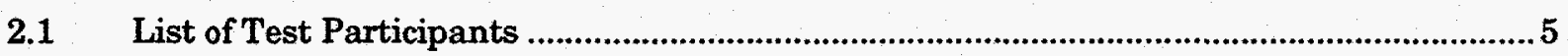

$2.2 \quad$ Hardware and Software of Each Participant ........................................................................

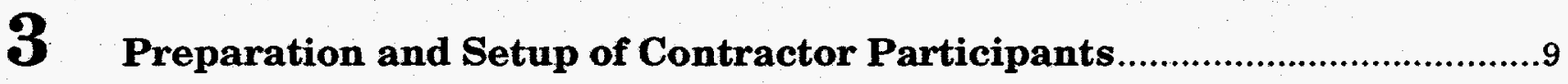

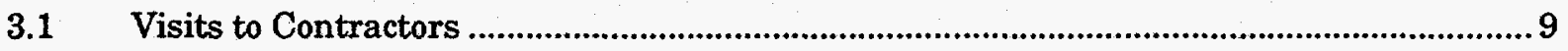

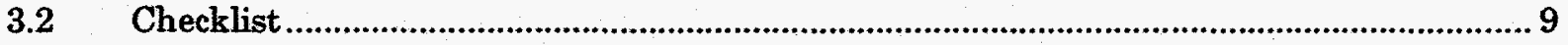

3.3 Modems and Software Sent to Participants ....................................................................... 10

3.4 Setting up VAN User Accounts for Participants ................................................................ 10

\section{Preparation and Setup of SM-ALC Systems and Processes........................ 11}

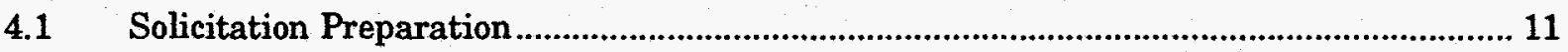

4.1.1 Descriptions of Base Contracting Systems .............................................................. 11 


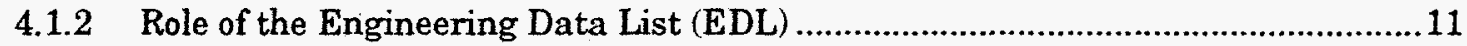

4.1.3 Description of Current Business Process ..................................................................11

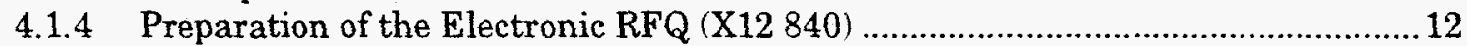

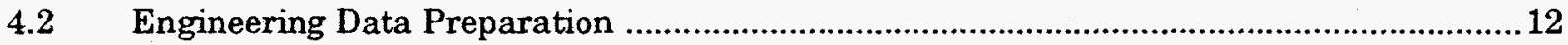

4.2.1 Description of Base Engineering Data Repository -- EDCARS ..............................12

4.2.2 Description of Current Engineering Data Retrieval Process ...................................12

4.2.3 Data Preparation for EDI Transaction Set (X12 841) ......................................... 12

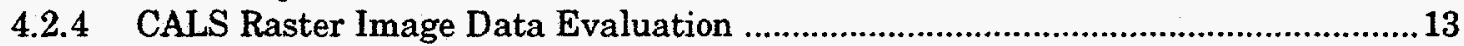

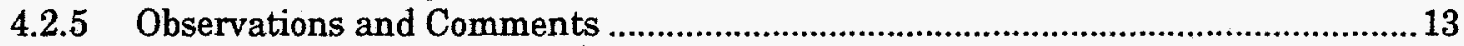

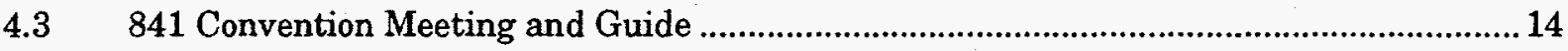

5 Collecting, Merging, and Transmitting Solicitation Data ..........................15

5.1 Transferring Engineering Data from EDCARS to Site IGP ....................................15

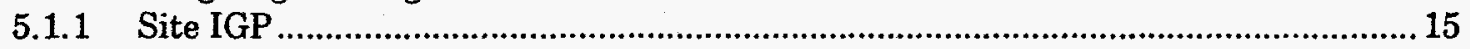

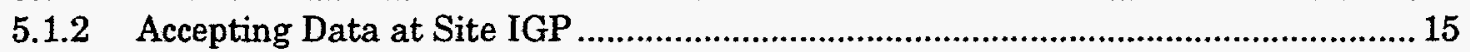

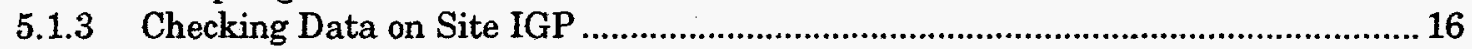

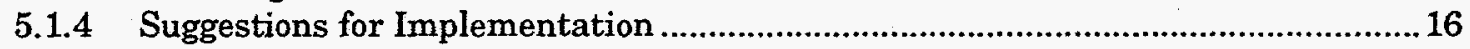

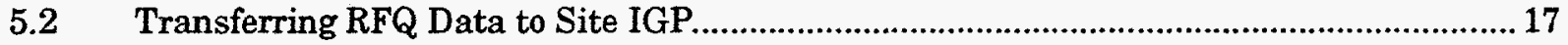

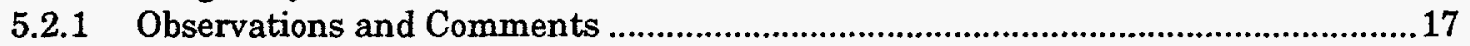

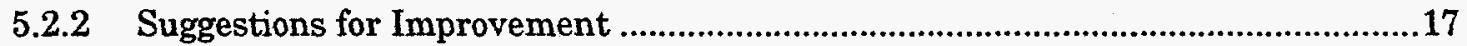

5.3 Merging Technical (CALS) and Business (RFQ) Data ...................................................17

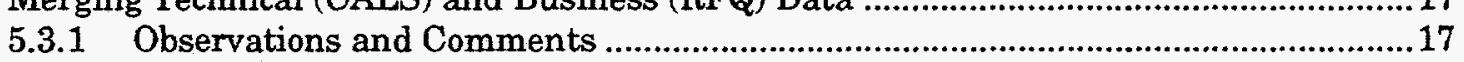

$5.4 \quad$ Transmitting Solicitations to Contractors ........................................................................ 17

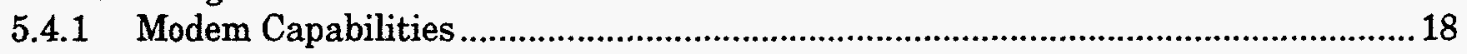

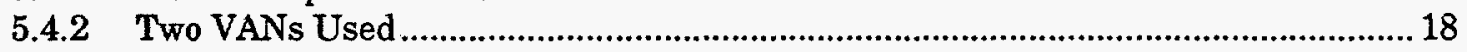

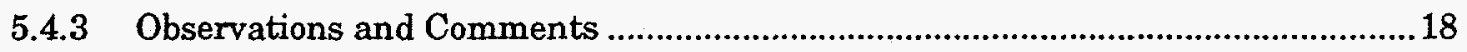

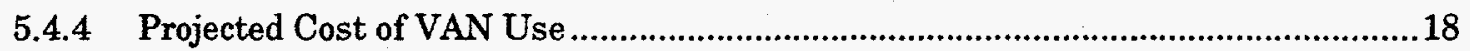

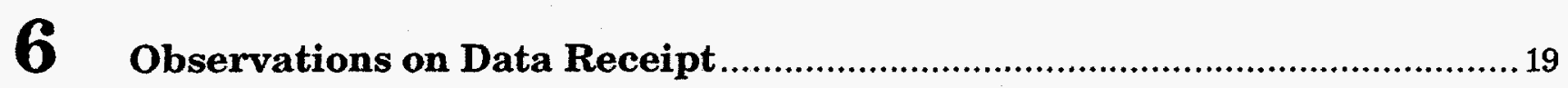

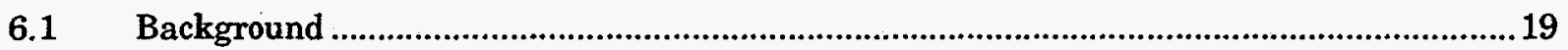

6.1.1 Necessary Hardware and Software Capabilities for Data Receipt ..........................19

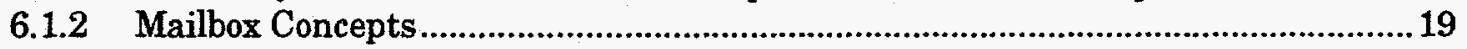

6.1.3 Software to Download and Translate EDI Messages ........................................20

$6.2 \quad$ Observations and Comments ...................................................................................................20

6.2.1 No Control Over Download or Message Selection.................................................20

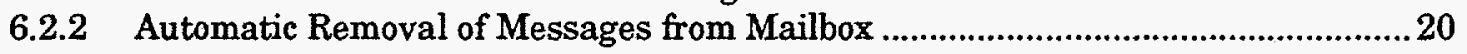

6.2.3 Business Computer Tied Up for Long Periods ..................................................20

6.2.4 Access to Faster Transmission Rates ................................................................21

6.2.5 Organization of Files on Local System .............................................................. 21

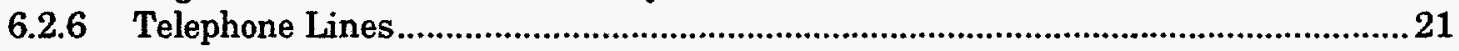

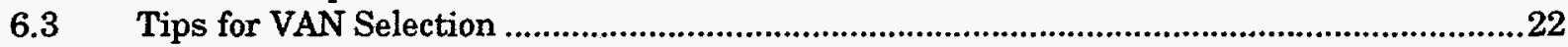

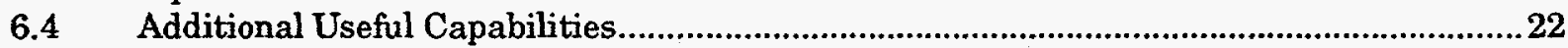




\section{Observations on Data Usability}

7.1 Background

7.1.1 Necessary Hardware and Software Capabilities for Data Display ...........................23

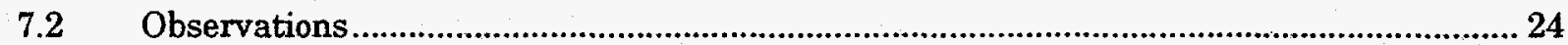

7.1.2 Details About the Software Used

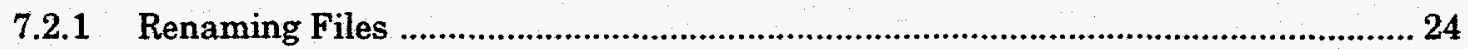

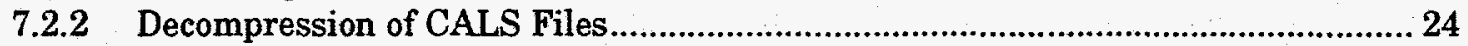

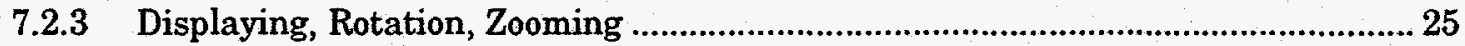

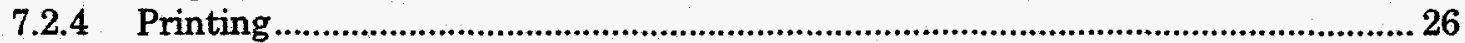

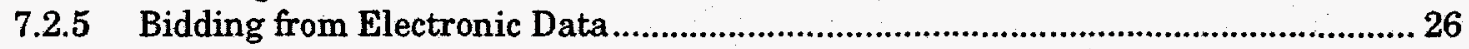

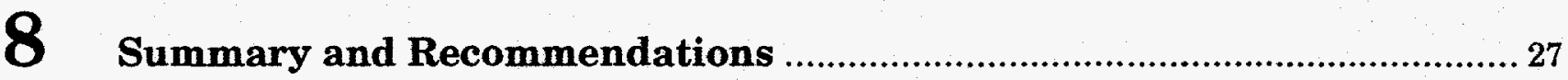

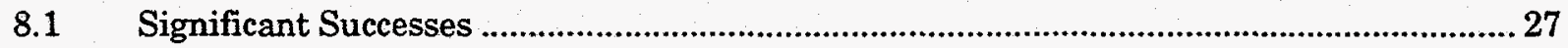

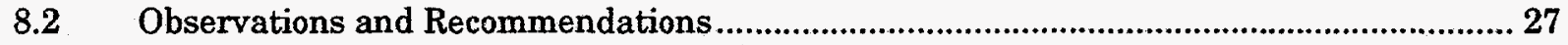

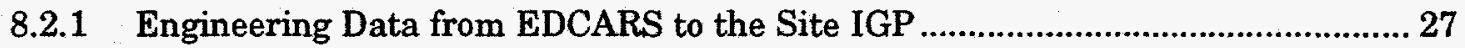

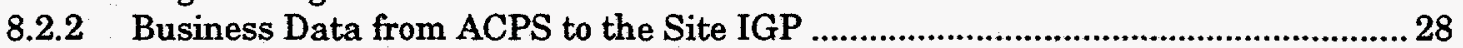

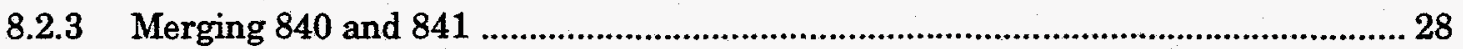

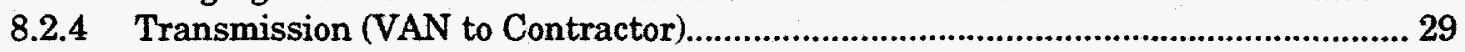

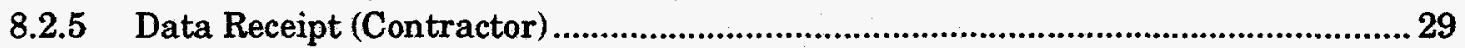

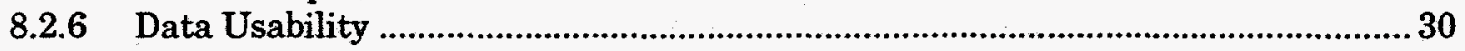

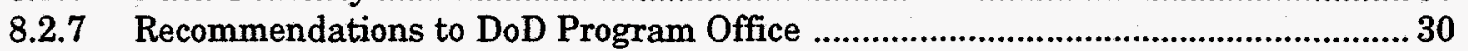

8.2.8 Recommendations to Future Implementors ....................................................... 31

\section{TABLES}

Table 1.1 Modems used by SM-ALC to access VANs ...............................................................4

Table 1.2 EDI translator software packages used for test ..............................................................4

Table 1.3 Raster decompression and display software packages used for test ............................. 4

Table 2.1 Hardware and software used by Sacramento Air Logistics Center (SM-ALC), McClellan AFB, CA

Table 2.2 Hardware and software used by AFCTN Test Bed, LLNL .............................................

Table 2.3 Hardware and software used by contractor participants........................................... 8

\section{FIGURES}

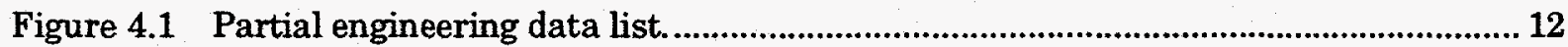

Figure 5.1 Listing of CALS MIL-STD-1840A data file header records for 3 bid set image files 15

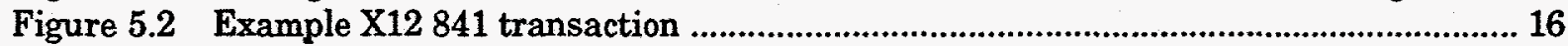

Figure 8.1 Functional block diagram of a hypothetical base-wide EDI implementation............. 31 
This Page Intentionally Left Blank 


\begin{abstract}
This report provides a summary of the Air Force CALS Test Network (AFCTN) Test Report Transfer of Air Force Technical Procurement Bid Set Data to Small Businesses, Using CALS and EDI (AFCTN Test Report 94-034, UCRL-ID-118619). It represents a synthesis of the results, conclusions, and recommendations, as well as a more concise presentation of the issues and strategies as viewed from AFCTN's perspective.
\end{abstract}

This report documents a test transfer of three Air Force technical procurement bid sets to one large and twelve small businesses, using the Department of Defense (DoD) Continuous Acquisition and Life-cycle Support (CALS) and ANSI ASC X12 Electronic Data Interchange (EDI) standards. The main goal of the test was to evaluate the effectiveness of using CALS technical data within the context of the DoD's EDIbased standard approach to electronic commerce in procurement, with particular emphasis on receipt and use of the data by small contractors. Air Force procurement data was provided by the Sacramento Air Logistics Center at McClellan Air Force Base; the manufacturing participants were selected from among McClellan's "Blue Ribbon" contractors, located throughout the United States. The test was sponsored by the Air Force CALS Test Network, headquartered at Wright-Patterson Air Force Base.

The test successfully demonstrated the technical feasibility of including CALS MIL-R-28002 (Raster) engineering data in an EDI Specification/Technical Information transaction set (ANSI ASC X12 841) when issuing electronic requests for quotation to small businesses. In many cases, the data was complete enough for the contractor participant to feel comfortable generating a quote. Lessons learned from the test are being fed back to the CALS and EDI standards organizations, and to future implementors of CALS-EDI based acquisition or contracting systems, which require the transfer of technical information, such as engineering data, manufacturing process data, quality test data, and other product or process data, in the form of a CALS or other digital datafile.

This work was performed under the auspices of USDOE by LLNL under contract no. W-7405-Eng-48. 
This Page Intentionally Left Blank 


\section{Executive Summary}

This test has demonstrated that Continuous Acquisition and Life-cycle Support (CALS) and Electronic Data Interchange (EDI) can be successfully combined to provide an electronic Request for Quotation (RFQ) capability in military acquisition and/or contracting operations, when acquiring technical parts, or replenishing LRUs (Lowest Replacement Units), from small manufacturing contractors. The test also identified several issues, summarized below, that need to be addressed when developing a production CALS and EDI based implementation.

This test, properly called a "demonstration" or "validation," tracked the transfer of actual Air Force Technical Procurement RFQ data from McClellan Air Force Base to one large and twelve small manufacturing businesses located throughout the United States. The test was limited to bid sets for procurement actions of less than $\$ 25,000$. Engineering drawings in CALS raster format were retrieved from the Sacramento Air Logistics Center's Engineering Data Computer Assisted Retrieval System (EDCARS), located at McClellan AFB, California, inserted into EDI transaction sets, and transferred via commercial telecommunications value-added networks (VANs) to the thirteen participating businesses. The businesses received the RFQ technical data, using modems and their existing phone lines, and viewed it on their local micro computers, generating images generally clear enough to permit a response to the RFQ. The businesses represented diverse manufacturing capabilities such as milling, sheet metal working, electromechanical assembly, motor construction, and plastics molding for windows and cockpits.

The major observations and accompanying recommendations from the test are:

1. The current contracting process could be streamlined by creating a direct electronic connection among the relevant on-base computer systems.

2. The test included Ethernet TCP/IP transfer of technical data between EDCARS and procurement computational resources. This activity indicated that direct access between these entities requires reconciliation between the ongoing EDCARS production activity and SM-ALC LAN loading/routing strategies, and the availability of procurement digital storage resources.

[Editor's note: It is anticipated that DoD engineering repository migration to JEDMICS will address many of these issues.]

3. The DoD Implementation Conventions for the ANSI ASC X12 840 and 841 transactions sets, and ANSI ASC X12 itself, if necessary, should be modified to allow mutual pointers, breaking up of large multi-file technical solicitations, transfer of engineering data lists, and requests for specific engineering drawings.

[Editor's note: Modifications to the DoD Implementation Conventions, and to the ANSI ASC X12 standards have been made to support these recommendations.]

4. Transmission times were lengthy, primarily due to large data set sizes. Therefore, until technology advances sufficiently to ensure feasibility of larger transmissions, data transmission should occur at 9600 baud or faster, and data sets larger than 5 megabytes should be transferred on other media (e.g., tapes, floppies, CDs) instead of over an EDI VAN.

5. Contractor participants were unable to selectively download messages from the VANs. As a result, the VANs used in this test have now implemented a capability which gives the user flexibility and control over the data download process.

6. Contractors should perform a business process analysis as they implement electronic contracting, in order to plan for the changes CALS and EDI will have on their daily business activities. 
7. Depending on the hardware, software, and configuration parameters used, some contractors were more successful than others in assimilating the electronic messages and utilizing the digital CALS images. Further evaluation of contractor business processes, engineering processes, and the computational resources available in the commercial market, is necessary.

8. The information handling knowledge and experience of the contractor also affected the ease with which the contractor could integrate the electronic RFQs into his daily business. Further evaluation of the education, checklists, and implementation aids and tools that are needed for a small business to more easily and effectively use electronic contracting is necessary. Integrated CALS-EDI training products and services also must be developed specifically for small contractors. 


\section{Purpose, Objectives, and Background}

\subsection{Purpose}

The purpose of this test was to evaluate the effectiveness of using Continuous Acquisition and Life-cycle Support (CALS) data within the context of the Department of Defense's (DoD's) standard approach to electronic commerce (EC) in procurement. This approach is based on the American National Standards Institute (ANSI) Accredited Standards Committee (ASC) X12 Standard for Electronic Data Interchange (EDI). A significant aspect of the test was its emphasis on procurement actions involving small businesses. Experience gained from the test will be used to support a subsequent pilot implementation of an electronic procurement system at Sacramento Air Logistics Center, McClellan Air Force Base, California, which will employ the CALS and EDI standards.

\subsection{Objectives}

The primary objective of the test was to demonstrate that, for the purpose of soliciting a request for quotation (RFQ), EDI can be used to successfully transmit CALS data to small businesses. Another was to demonstrate to small businesses the benefits of receiving and using CALS digital images.

To organize the test, and to support these objectives, the following were demonstrated and evaluated:

1. Direct electronic extraction of procurement-related CALS data from the Engineering Data Computer Assisted Retrieval System (EDCARS);

2. Electronic transfer of the technical data portion of an RFQ, namely the $\mathrm{X} 12$

Specification/Technical Information (841) transaction set, to the Air Force CALS Test Network at Lawrence Livermore National Laboratory (LLNL) for CALS evaluation;

3. Distribution of the package to selected small businesses, including a small business co-op center, using EDI over commercial Value Added Networks (VANs); and

4. Capture and display of the RFQ's CALS data by the contractor participants.

\subsection{Background}

\subsubsection{Summary of Air Force CALS Test Network CALS-EDI Testing}

This is the third test involving the exchange of CALS data via EDI transaction sets which the Air Force CALS Test Network (AFCTN) Test Bed at LLNL has conducted. The first test, performed in the fall of 1990, was a demonstration of the basic compatibility of CALS and EDI. It showed that CALS data could be packaged in an EDI transaction set, sent over ISDN or DDN lines, and arrive intact and usable on the other end. It also showed that the time to transmit an engineering drawing over DDN, even during a "heavy use" time of day, was well under ten minutes.

The second test, performed in the fall of 1991, successfully demonstrated a paperless Air Force technical procurement transaction. Engineering drawings from an actual solicitation bid set were extracted in CALS raster format from the McClellan AFB CA EDCARS system, sent electronically using STX software from Supply Tech to a temporary VAN hub distribution point, then forwarded to a prospective contractor. The EDI-experienced contractor, TRW, successfully received the transactions using the same EDI software, and displayed the CALS raster images using HiJaak software from Inset Systems, Inc. This demonstrated an ability to send RFQs electronically using CALS and EDI.

This third test, a demonstration/validation, was actually a modification of the previous Air Force procurement test. This activity differs from the previous test in that specific recipients were targeted. 
The RFQ and technical data were sent to a representative sample of mostly small manufacturing contractors, who had various levels of exposure to CALS and EDI. Two VAN-based routes were used to transfer the procurement data to the contractors: (1) directly to contractors, and (2) to contractors through a central contractor co-op. The co-op transfer is described in a separate report, CALS/EDI Test With Small Businesses, available from the Brigham Young University CALS Shared Resource Center.

\subsubsection{Nature of the Test}

This test is best described as a "demonstration/validation." Although not a strict business case analysis, it does address usability, quality, and convenience of electronic dissemination of technical solicitations. Comparisons are made between conventional data transfers (aperture cards delivered through the U.S. mail) and electronic transfers (CALS digital images delivered by commercial VANs). The VAN costs described in this report are best guess estimates. Much of the hardware and software anticipated as necessary for the test was provided to the participants without charge; there were no metrics to determine the optimization of the various system/software/hardware integrations.

The test demonstrated that CALS standards can be used effectively in actual government EDI procurement. Problems encountered during the test have been identified and solutions recommended.

\subsubsection{Testing Strategy}

The approach taken by the Air Force CALS Test Network in executing complicated tests such as this is to describe the ideal procedure in a test plan, execute the test using prudence and reasonable backup strategies, then report the actual test events, including any deviations from the original plan.

Since this test depended upon availability of several capabilities beyond the control of the AFCTN, the strategy taken was to execute the test over an extended period of time, with sufficient flexibility to incorporate capabilities as they became available. In the event the capabilities did not become available during the test, "fallbacks" or "workarounds" were used to accommodate the test plan.

\subsubsection{Testing Procedures}

The testing procedures or steps followed during the test are detailed in the Test Plan. In general, they involved bringing bid set data (business data and engineering drawings) to an Intelligent Gateway Processor (IGP) located at the originator's site, inserting the data into X12 840 and 841 transaction sets, and forwarding them to a VAN. The contractors would access their VAN "mail boxes" to see that the transaction sets had been delivered, download them to their PCs, and decompress and view the files.

\subsubsection{Standards and Specifications Tested}

The test used actual solicitation bid sets for RFQs. These packages contained numerical and textual data, in ASCII format, from the McClellan Air Force Base CA Sacramento Air Logistics Center (SMALC) Automated Contract Preparation System (ACPS). Along with the text were supporting engineering drawings and specifications in CALS raster format from the SM-ALC EDCARS system.

The specific standards utilized or evaluated were:

a. DoD MIL-STD-1840A - Automated Interchange of Technical Information

b. DoD MIL-R-28002A - Raster Graphic Representation in Binary Format, Requirements for

c. ANSI ASC X12 Request for Quotation (840) transaction set, Version 3022 
d. ANSI ASC X12 Specification/Technical Information (841) transaction set, Version 3022

e. ANSI ASC X12 Functional Acknowledgment (997) transaction set, Version 3010

f. X.400 Open System Interconnection (OSI) Message Handling System (an International Consultative Committee on Telegraphy and Telephony [CCITT] Standard)

\subsubsection{Test Schedule}

Every major deadline in the test plan schedule was met. Details of the schedule are in the Test Plan.

\subsection{Collaboration With SM-ALC}

The test was a joint effort between Aircraft Contracting at SM-ALC and the Air Force CALS Test Network Test Bed at LLNL. SM-ALC provided most of the management and coordination; AFCTN assisted, wrote the Test Plan, provided CALS-specific technical expertise, and coordinated, edited, and produced this report. Funding was provided by the Air Force CALS Program Office. The SM-ALC Aircraft Contracting Division, which supports the F-111, A-7, and A-10 aircraft, collected the technical data from its engineering technical data repository, EDCARS, and packaged the data into electronic solicitations or "bid sets."

\subsection{Philosophy of Test}

Commercial off the shelf (COTS) software and hardware was utilized wherever possible, e.g., the PC systems and CALS conversion and viewing software used by the contractor participants, and the EDI software used by all participants. Three solicitations with varying numbers of technical drawings were identified so that solicitation size statistics could be gathered. The different sized solicitations also provided useful statistics on the relationships between size and transmission time, and the time required to gather and send $35 \mathrm{~mm}$ aperture cards compared with that of sending electronic files.

\subsection{Use of COTS Hardware and Software}

The testing team considered it a requirement to use easily obtainable commercial products. Execution of the test using COTS components was considered critical to the interest in, and acceptance of these test results, particularly to small business contractors.

Platforms used for the test ranged from DOS/Intel-based microcomputers (PCs) and Apple Macintoshes to Data General and IBM-like mainframes, and included UNIX workstations and mid-range systems. VANs were used to transport the solicitations; workstation and micro-based EDI translation software were used to build and interpret the transaction sets.

\subsubsection{Hardware}

A microprocessor (PC-compatible or Macintosh) computer was used by each contractor to run the EDI software. These computers had 2 megabytes or more of RAM, and sufficient hard disk space to store the largest expected compressed solicitation, approximately 8.6 megabytes. The restored (decompressed) file could be $40-50$ times larger than the incoming compressed file.

The hardware platform used at SM-ALC to run the EDI translator software which packaged and sent the solicitations to the contractors was an existing UNIX-based AT\&T 3B2 computer. Modems used to access the VANs, shown in Table 1.1, could operate at transfer rates of up to 9600 baud. During the test, 2400 and 9600 baud transfer rates were used. 


\begin{tabular}{|ll|}
\hline Make & Model \\
Hayes & V-series ULTRA Smartmodem 9600 \\
Zenith & ZM-2401 \\
Datatrek & $12 / 2400$ \\
\hline
\end{tabular}

Table 1.1 Modems used by SM-ALC to access VANs.

\subsubsection{Software}

EDI translator software is necessary to receive and send EDI messages and transactions. There are numerous EDI translator software packages available on the commercial market which function on most processors, such as IBM PC compatible, Macintosh, and UNIX desktops, most engineering workstations, and mainframe computers. Table 1.2 lists the EDI translator software packages used for the test. These had demonstrated, before 1991, the ability to handle binary files of technical data via the X12 841 transaction set (additional commercial software is now also available from a few vendors):

$\begin{array}{llll}\text { Hardware Platform } & \text { EDI Translator } & & \text { Manufacturer } \\ \text { PC and compatibles } & \text { STX } & & \text { Supply Tech, Inc. } \\ \text { Macintosh } & \text { MacEDI } & & \text { Digit Software } \\ \text { AT\&T 3B2 (UNIX) } & \text { Datatran } & & \text { St. Paul Software }\end{array}$

Table 1.2 EDI translator software packages used for test.

Display software is necessary for examining raster technical data transferred by EDI. Table 1.3 lists the decompression, reformatting, and display software packages which were used during the test:

\begin{tabular}{|lcccc|}
\hline & Decompress & & Rotate \& & Convert \& \\
Software & CALS Raster & Display & Zoom, etc. & Reformat \\
HiJaak for Windows & $\mathrm{X}$ & $\mathrm{X}$ & $\mathrm{X}$ & $\mathrm{X}$ \\
Myriad & $\mathrm{X}$ & $\mathrm{X}$ & $\mathrm{X}$ & $\ldots$ \\
Paintbrush & -- & $\mathrm{X}$ & $\mathrm{X}$ & - \\
\hline
\end{tabular}

Table 1.3 Raster decompression and display software packages used for test.

Other comprehensive software applications perform all the functions in the above table. For example, a CAD software application which can handle incoming compressed CALS technical data should be capable of performing all the necessary functions for displaying and manipulating the files.

\subsection{Structure of This Report}

This report is structured to follow the flow of the bid set data. The next three sections describe the participants, with their respective hardware and software platforms, and the necessary pre-test preparation. Sections 5 through 7 contain descriptions and observations of the data flow to the site IGP, to the VANs, and finally to the small business contractors. The final section summarizes the successes, problems, and recommendations that came from the test. 


\section{Test Participants and Platforms}

The contractors who participated in this test were selected based on criteria established by the Air Force. SM-ALC, as the primary government organization seeking to implement the electronic transmission of binary data via the X12 841 transaction set, determined that a number of small businesses should be invited, at no cost to them or to the government, to participate in this test. SM-ALC utilized its Blue Ribbon Contractors, who are exceptional contractors selected from the over 6,200 contractors SM-ALC contracted with in the previous fiscal year. Of the thirteen Blue Ribbon contractors named by SM-ALC at the time of this test, eight chose to participate. An additional five contractors participated via a contracting vendor co-op, located at Brigham Young University (BYU), which provided VAN connectivity for these contractors.

\subsection{List of Test Participants}

\section{Air Force Contracting}

Aircraft Contracting Division DE/CALS Project

Sacramento Air Logistics Center (SM-ALC/PK)

3237 Peacekeeper Way, Suite 17

McClellan AFB, CA 95652-1059

916-643-6200

916-643-2885 FAX

edi@smcdm02.sm.aflc.af.mil

\section{SM-ALC Contractor Affiliates}

Allied-Signal Airesearch

19201 Susana Road

Rancho Dominquez, CA 90221

Inspirnetics

9330 7th Street, Unit E

Rancho Cucamonga, CA 91730

714-941-8303 FAX

Llamas Plastics Inc.

12970 Bradley Avenue

Sylmar, CA 91342

818-362-9780 FAX

Moda Magnetics Corp.

84 Rome Street

Farmingdale, NY 11735

516-249-2792 FAX
American Electronics

1600 East Valencia Drive

Fullerton, CA 92631

714-871-1403 FAX

Kent Associates, Inc.

900 Fifth Avenue

Mansfield, TX 76063-2727

817-473-6705 FAX

Micro Systems, Inc.

65 Hill Avenue

Fort Walton Beach, FL 32548

904-243-1378 FAX

Precision Manufacturing of San Antonio, Texas

4546 Sinclair Road

San Antonio, TX 78222

210-648-7401 FAX 


\section{Participating VANs}

Advantis Systems

AT\&T

3405 West Martin Luther King Blvd.

3221 McKelvey Road, Suite 201

Tampa, FL 33607

813-878-5298 FAX

Bridgeton, MO 63044

314-770-3224 FAX

\section{EDI Software Vendors}

Digit Software

P. O. Box 1425

Silver Spring, MD 20915

301-593-2201 FAX

St. Paul Software

754 Transfer Road

St. Paul, MN 55114-1404

612-641-0609 FAX

Supply Tech, Inc.

1000 Campus Drive

Ann Arbor, MI 48104-6700

313-998-4099 FAX

\section{TRW CALS-EDI Information Systems contact}

TRW Systems Integration Group

One Space Park

Redondo Beach, CA 90278

310-545-8475 FAX

\section{X12 841 DoD Implementation Convention contact}

Logistics Management Institute

2000 Corporate Ridge

McLean, VA 22102-7805

301-320-5617 FAX

\section{CALS Software Vendor contact}

Inset Systems Inc.

71 Commerce Drive

Brookfield, CT 06804-3405

203-775-5634 FAX

\section{Air Force CALS Test Network}

AFCTN Test Bed

Automated Interchange of Technical Information Project

Technology Information Systems Program

Lawrence Livermore National Laboratory

P.O. Box 808, L-542

Livermore, CA 94551

510-424-5054 FAX 


\subsection{Hardware and Software of Each Participant}

\begin{tabular}{|c|c|c|c|c|c|}
\hline & Hardware & $\begin{array}{l}\text { Operating } \\
\text { System }\end{array}$ & Software & Communications & $\begin{array}{l}\text { Other } \\
\text { Information }\end{array}$ \\
\hline Site IGP & $\begin{array}{l}\text { AT\&T 3B2 600G } \\
24 \mathrm{MHz} \\
\text { processor, dual } \\
\text { processor } \\
\text { enhancements }\end{array}$ & $\begin{array}{l}\text { System V } \\
\text { Release 3.2.2 }\end{array}$ & $\begin{array}{l}\text { Wollongong } \\
\text { WIN3B TCP/IP, } \\
\text { RFS, Ascent 2.0, } \\
\text { St. Paul } \\
\text { Software's } \\
\text { Datatran }\end{array}$ & $\begin{array}{l}\text { lobase5 } \\
\text { Ethernet, eport } \\
\text { \& fxm } \\
\text { asynchronous } \\
\text { ports }\end{array}$ & $\begin{array}{l}64 \text { Mbyte } \\
\text { memory, } 1.2 \\
\text { Gbyte disk }\end{array}$ \\
\hline EDCARS System & $\begin{array}{l}\text { IPL Systems Inc. } \\
\text { Model } 4460 \text { (IBM } \\
\text { plug compatible) }\end{array}$ & MVS & EDCARS System & $\begin{array}{l}\text { COM10 (TCP/LP, } \\
\text { Arcnet, X.25) }\end{array}$ & \\
\hline ACPS System & $\begin{array}{l}\text { Data General } \\
\text { MV-9500 }\end{array}$ & AOS/VS.2 & $\begin{array}{l}\text { ACPS, } \\
\text { WordPerfect }\end{array}$ & $\begin{array}{l}\text { Ethernet, TCP/P } \\
\text { (SMTP not fully } \\
\text { implemented) }\end{array}$ & $\begin{array}{l}\text { Tape interface to } \\
\text { Xerox } 9700 \\
\text { printer }\end{array}$ \\
\hline LMS System & IBM $3090-200$ & MVS & $\begin{array}{l}\text { Logistics } \\
\text { Modernization } \\
\text { System (LMS), } \\
\text { Stock Control } \\
\text { and Distribution } \\
\text { (SC\&D), } \\
\text { Contract Data } \\
\text { Management } \\
\text { System (CDMS) }\end{array}$ & $\begin{array}{l}\text { Serial Kermit, } \\
\text { Open Link } \\
\text { TCP/P on } \\
\text { COM10 F.E.P. }\end{array}$ & \\
\hline
\end{tabular}

Table 2.1 Hardware and software used by Sacramento Air Logistics Center (SM-ALC), McClellan AFB, CA.

\begin{tabular}{|c|c|c|c|c|c|}
\hline & Hardware & $\begin{array}{l}\text { Operating } \\
\text { System }\end{array}$ & Software & Communications & Graphics \\
\hline Sun 4 & $\begin{array}{l}\text { SPARCstation } \\
\text { IPC, } 24 \text { Mbyte } \\
\text { memory, } 2 \text { Gbyte } \\
\text { hard disk }\end{array}$ & \begin{tabular}{|l|} 
SunOS Version \\
4.1, Release 4.1.1 \\
(UNIX)
\end{tabular} & $\begin{array}{l}\text { AFCTN Tapetool, } \\
\text { MIL-STD-1840A } \\
\text { evaluation } \\
\text { software, Open } \\
\text { Windows }\end{array}$ & Internet & \\
\hline Sun 3 & $\begin{array}{l}\text { Sun } 3 / 60,4 \\
\text { Mbyte memory, } \\
500 \text { Mbyte hard } \\
\text { disk }\end{array}$ & $\begin{array}{l}\text { SunOS Version } \\
4.1 .3\end{array}$ & $\begin{array}{l}\text { CALSTB.350, } \\
\text { Paintbrush }\end{array}$ & Internet & \\
\hline IBM PC & $\begin{array}{l}\text { IBM PS/2 model } \\
60,2 \text { Mbyte } \\
\text { memory, } 30 \\
\text { Mbyte hard disk }\end{array}$ & MS-DOS 3.3 & $\begin{array}{l}\text { ValidG4, HiJaak, } \\
\text { Viewer, Myriad, } \\
\text { DecompG4 }\end{array}$ & Internet & $\overline{\mathrm{CGA}}$ \\
\hline
\end{tabular}

Table 2.2 Hardware and software used by AFCTN Test Bed, LLNL. 


\begin{tabular}{|c|c|c|c|c|c|}
\hline & Hardware & $\begin{array}{l}\text { Operating } \\
\text { System }\end{array}$ & Software & Communications & Graphics \\
\hline $\begin{array}{l}\text { Allied-Signal } \\
\text { Airesearch } \\
\text { (Large Business) }\end{array}$ & $\begin{array}{l}\text { AST Bravo } 386, \\
100+\text { Mbyte hard } \\
\text { disk with } 10+ \\
\text { Mbyte available }\end{array}$ & $\begin{array}{l}\text { MS-DOS } 5.0 \text { with } \\
\text { Windows } 3.0\end{array}$ & $\begin{array}{l}\text { STX, HiJaak for } \\
\text { Windows }\end{array}$ & $\begin{array}{l}9600 \text { baud } \\
\text { Modem }\end{array}$ & VGA \\
\hline $\begin{array}{l}\text { American } \\
\text { Electronics } \\
\text { (Small Business) }\end{array}$ & $\begin{array}{l}\text { IBM XT (386), } 80 \\
\text { Mbyte hard disk } \\
\text { with } 10 \text { Mbyte } \\
\text { available }\end{array}$ & $\begin{array}{l}\text { MS-DOS } 3.3 \text { with } \\
\text { Windows }\end{array}$ & STX & $\begin{array}{l}\text { Hayes } 1200 \text { baud } \\
\text { Modem }\end{array}$ & EGA \\
\hline $\begin{array}{l}\text { Inspirnetics } \\
\text { (Small Business) }\end{array}$ & $\begin{array}{l}486 \mathrm{DX}-25 \mathrm{MHz} \\
\text { IBM compatible, } \\
120 \text { Mbyte hard } \\
\text { disk with } 10+ \\
\text { Mbyte available }\end{array}$ & $\begin{array}{l}\text { MS-DOS } 5.0 \text { with } \\
\text { Windows } 3.1\end{array}$ & $\begin{array}{l}\text { HiJaak for } \\
\text { Windows Version } \\
1.0, \text { STX Version } \\
2.5\end{array}$ & $\begin{array}{l}\text { Hayes ULTRA 96 } \\
\text { Modem }\end{array}$ & Super VGA \\
\hline $\begin{array}{l}\text { Kent Associates, } \\
\text { Inc. (Small } \\
\text { Business) }\end{array}$ & $\begin{array}{l}\text { Leading } \\
\text { Technology } 386 \\
\text { SX-16, } 180 \\
\text { Mbyte hard disk } \\
\text { with } 20+\text { Mbyte } \\
\text { available }\end{array}$ & $\begin{array}{l}\text { MS-DOS } 3.3 \text { with } \\
\text { Windows } 3.1\end{array}$ & $\begin{array}{l}\text { HiJaak for } \\
\text { Windows } 1.0, \\
\text { STX Version } 2.5\end{array}$ & $\begin{array}{l}\text { Hayes } 9600 \text { baud } \\
\text { Modem }\end{array}$ & $\overline{V G A}$ \\
\hline $\begin{array}{l}\text { Llamas Plastics } \\
\text { Inc. (Small } \\
\text { Business) }\end{array}$ & $\begin{array}{l}286 \text { IBM } \\
\text { compatible, } 80 \\
\text { Mbyte hard disk } \\
\text { with } 20+\text { Mbyte } \\
\text { available }\end{array}$ & MS-DOS 5.0 & $\overline{\mathrm{STX}}$ & Practical 2400 & \\
\hline $\begin{array}{l}\text { Micro Systems, } \\
\text { Inc. (Small } \\
\text { Business) }\end{array}$ & $\begin{array}{l}\text { Hewlett-Packard } \\
386,80 \text { Mbyte } \\
\text { hard disk with } \\
10+\text { Mbyte } \\
\text { available, and } \\
486 \text { IBM } \\
\text { compatible, } 200 \\
\text { Mbyte hard disk }\end{array}$ & $\begin{array}{l}\text { MS-DOS } 5.0 \text { with } \\
\text { Windows } 3.0\end{array}$ & \begin{tabular}{|l|} 
HiJaak for \\
Windows Version \\
1.0, STX Version \\
2.5, AT\&T \\
Easylink, \\
Interface Version \\
1.2
\end{tabular} & $\begin{array}{l}\text { Hayes } 2400 \text { baud } \\
\text { Modem, } \\
\text { MultiTech } 9600 \\
\text { baud Modem (on } \\
\text { loan from LLNL) }\end{array}$ & $\overline{\text { EGA }}$ \\
\hline $\begin{array}{l}\text { Moda Magnetics } \\
\text { Corp. (Small } \\
\text { Business) }\end{array}$ & $\begin{array}{l}\text { Gateway } 2000 \\
486 \text { DX } 33,80 \\
\text { Mbyte with } 10+ \\
\text { Mbyte available }\end{array}$ & $\begin{array}{l}\text { MS-DOS } 5.0 \text { with } \\
\text { Windows } 3.1\end{array}$ & $\begin{array}{l}\text { HiJaak for } \\
\text { Windows, STX }\end{array}$ & $\begin{array}{l}\text { MultiTech } 9600 \\
\text { baud Modem (on } \\
\text { loan from LLNL) }\end{array}$ & VGA (available) \\
\hline $\begin{array}{l}\text { Precision } \\
\text { Manufacturing of } \\
\text { San Antonio, } \\
\text { Texas (Small } \\
\text { Business) }\end{array}$ & $\begin{array}{l}486 \text { IBM } \\
\text { compatible, 10+ } \\
\text { Mbyte available } \\
\text { on hard disk }\end{array}$ & $\begin{array}{l}\text { MS-DOS } 5.1 \text { with } \\
\text { Windows } 3.0\end{array}$ & $\begin{array}{l}\text { HiJaak for } \\
\text { Windows, STX }\end{array}$ & $\begin{array}{l}\text { Hayes } 2400 \text { baud } \\
\text { Modem }\end{array}$ & \\
\hline
\end{tabular}

Table 2.3 Hardware and software used by contractor participants. 


\section{Preparation and Setup of Contractor Participants}

\subsection{Visits to Contractors}

Each of the eight participating contractors were personally visited by a pre-test briefing team made up of representatives from SM-ALC Contracting Management and Information Systems, the Air Force CALS Test Network Test Bed at LLNL, the TRW Systems Integration Group, and Supply Tech, Inc. VAN and other EDI software vendor representatives also took part in some of these visits. The objective of these visits was to inform each contractor of 1) the test objectives, and 2) how these efforts were part of the larger on-going movement in both industry and government to use recently evolved and commercially available digital information exchange technologies. As part of these visits, each contractor was also briefed on how this test fit into the government's overall CALS and EDI initiatives and, more specifically, the functions and responsibilities of the Air Force CALS Test Network. Additionally, the briefing team explained how these technologies are anticipated to eventually 1) become part of any future normal business environment, supporting business transactions with both government and industry, and 2) support and seamlessly integrate with all types of business transactions, including but not limited to purchase activities. The test was depicted as a first step toward electronically facilitating most, if not all, of any small business' information exchange needs. As a result of these visits, the briefing team perceived within each business an understanding that 1) this was an opportunity to learn in their own plant environment, 2) when the government and all their other trading partners implement EC/EDI, their business support costs could be reduced due to fewer telephone inquiries and overnight express packages, and 3 ) this capability could become a competitive business advantage when fully implemented.

The visits included explanations of the specific hardware and software being provided for the test, the VAN services that would be used, and the types of computers, applications software, phone connections and peripherals that were needed. In all cases, the test environment appeared to fit into each small business' available equipment and software without difficulty; most businesses operated the test independent of their applications, with only a few planning to integrate testing activities with their other applications and operating environment. The details of the test were discussed including the types, sizes, and other characteristics of the data to be transferred, the check lists to be completed, and both the normal and unusual observations to be made. The final items of discussion centered around the test scheduling and the detailed mechanics of each individual segment of the test. Every effort was made to schedule and perform the test so as to not interfere with each contractor's normal business activities.

\subsection{Checklist}

In an effort to help test participants to execute the test, and also to aid the collection of statistics about the test, the test team devised a checklist document. This document, which was patterned after the CALS Test Network Transfer Test Procedures Checklist, was divided into sections that were designed to lead the test participant through the steps necessary to execute the test. Each section of the checklist document contained questions pertinent to a specific aspect of the test. These questions were ordered and phrased so as to lead the test participant to the next step to be performed. The titles of the sections indicated whom was expected to complete that section. The document's introduction also provided guidance for completion of the checklist. This checklist document was distributed to the manufacturing participants soon after they had been visited by the testing team. The participants were instructed to make photocopies of pertinent sections of the checklist, and make a new entry for each transmission they received.

Some test participants found the questions in the checklist difficult to respond to, perhaps due to awkward or unfamiliar wording. The AFCTN has plans to refine and make available the checklist as part of a 
CALS-EDI test packet, which will be designed to help businesses become familiar with and prepare themselves for using EDI and CALS data in procurement actions.

\subsection{Modems and Software Sent to Participants}

Commercial vendors loaned 9600 baud modems to many of the contractor participants who did not already have such equipment. Two contractor participants borrowed MultiTech 9600 baud modems from the test team at LLNL. These modems were tested and configured at LLNL with the appropriate cables and switch settings before they were shipped to the contractors.

Each contractor participant received on loan a copy of STX12, an EDI translation software package from Supply Tech, Inc., and a copy of HiJaak for Windows, a raster image decompression and display tool from Inset Systems Inc.

\subsection{Setting up VAN User Accounts for Participants}

Supply Tech arranged for the establishment of user accounts for each of the participants on the appropriate VAN. Four contractor participants, Allied-Signal Airesearch, American Electronics, Inspirnetics, and Llamas Plastics Inc., were provided with mailboxes on the Advantis VAN, while the other participants, Micro Systems, Inc., Precision Manufacturing of San Antonio, Texas, Kent Associates, Inc., and Moda Magnetics Corp., utilized mailboxes on the AT\&T VAN.

For each of these participants, Supply Tech contacted the appropriate VAN, which provided a mailbox account number and password, then accessed each mailbox to make sure that its trading partner relationships were set correctly, then loaded each contractor's mailbox with a test 841 transaction. Next, they contacted each participant to give instructions for using the mailbox, and had each one download the test 841. This downloading procedure caused the Supply Tech STX12 EDI translation software at the contractor's site to automatically respond with a Functional Acknowledgment transaction (X12 997). Subsequently, Supply Tech verified with each contractor that the downloaded test 841 was consistent with the data that had been loaded into the mailbox. 


\section{Preparation and Setup of SM-ALC Systems and Processes}

Base contracting computer systems and engineering data computer archives provided the data used in this test. Section 2.2 lists the configurations of these systems. Section 4.1 describes the systems and processes which support the business aspects of aircraft contracting. Section 4.2 describes the systems and processes used to support Air Force technical item procurement engineering data.

\subsection{Solicitation Preparation}

The business data, obtained from ACPS and the Contract Data Management System (CDMS), included three Requests for Quote (RFQs) and their associated Engineering Data Lists (EDLs). The test team placed more significance on the sizes (in bytes) of the solicitations to be electronically transmitted than on their content. In order to select appropriate sizes, a sample of SM-ALC technical solicitations from May 1992 was taken. The size of each solicitation in the sample was determined by summing the image file sizes for each drawing on the EDL. Three solicitations were selected for testing, which represent the average small, average medium, and one of the largest solicitations in the sample. The sizes of these solicitations, as reported by EDCARS, were approximately $.65,1.84$, and 13.8 megabytes, and consisted of 5,10 , and 75 aperture cards, respectively.

\subsubsection{Descriptions of Base Contracting Systems}

\subsubsection{ACPS}

The RFQ is created in the Automated Contract Preparation System (ACPS), the contract writing system used at the five Air Logistics Centers (ALCs) in the Air Force Materiel Command (AFMC), which support acquisition of major weapon systems for spare parts and modification programs. ACPS runs on a Data General MV-9500. The users (contract personnel) access ACPS through a local area network (LAN) to create any needed contractual documentation. ACPS contains the logic of the Federal Acquisition Regulation (FAR), its supplements, and supporting regulations, to ensure that correct and current clauses, formats, and other regulatory requirements are incorporated into documents.

\subsubsection{SC\&D and CDMS}

The Stock Control and Distribution (SC\&D) system, which runs on an IBM 3090, provides on-line requisition processing, status of asset inventories, and furnishes both part usage and current status of asset balances to the Requirements Data Bank. CDMS, which runs on the same IBM 3090, interfaces with SC\&D and generates the EDL. This EDL is used by the technical data repository to create the solicitation technical data package.

\subsubsection{Role of the Engineering Data List (EDL)}

The RFQ references the EDL(s), which are generated by CDMS and refined interactively until they meet the requirements of the proposed purchase. The EDLs list all engineering, technical, or specification data applicable to the item. The final EDL(s) are printed out and then attached to the pages of the RFQ along with the aperture cards, which were generated by the EDCARS system for the solicitation.

\subsubsection{Description of Current Business Process}

In the current paper process, the user verifies the EDL and aperture cards, then creates the RFQ. Using a PC, the user accesses ACPS via a LAN. When the RFQ is completed, a printed copy is mailed, with the EDL and aperture cards, to interested contractors. 


\subsubsection{Preparation of the Electronic RFQ (X12 840)}

The process of preparing an X12 840 transaction consisted of obtaining a sample transaction and manually editing specific fields which described the buyer, sender, and product information from the RFQ, and adding a field which could be used to associate a specific 840 transaction with a specific 841 transaction. One 840 transaction was created for each of the three data sets. A manual approach was necessary primarily because no automated products that produced an 840 transaction set, which could be logically associated with an 841 transaction, were available. This was largely due to the lack of a formally defined mechanism in X12, at the time of the test, for an 840 to reference an 841 , a shortcoming that was subsequently accommodated by X12.

\subsection{Engineering Data Preparation}

\subsubsection{Description of Base Engineering Data Repository -- EDCARS}

The technical data used consisted of three released engineering data sets, obtained from SM-ALC EDCARS. The basic functionality of EDCARS is to provide a virtual aperture card storage facility that precludes the costly manual process of filing and retrieving microfilm records. EDCARS is limited to managing bitonal digital raster image data. The SM-ALC EDCARS system host is a main-frame IPL Systems Inc. Model 4460 computer, running the MVS operating system. The images are housed in several banks of optical disk jukeboxes. A database of the stored images is maintained to facilitate access and control. Document revision levels are recorded but not controlled by EDCARS.

\subsubsection{Description of Current Engineering Data Retrieval Process}

A printed hardcopy of the EDL is routed to EDCARS operators, who re-enter the data into an EDCARS system request for technical data. From this image retrieval request, EDCARS produces a deck of aperture cards which is provided to contracting where it is audited for completeness and applicability to the procurement. A master deck of aperture cards is used to generate RFQ distribution copies.

\subsubsection{Data Preparation for EDI Transaction Set (X12 841)}

Using the EDL, the appropriate data files were selected from SM-ALC EDCARS, and post-processed into the CALS MIL-R-28002 Type-I data format instead of aperture cards. This processing requires nontrivial systems resources in terms of both disk space and CPU cycles, and is therefore scheduled at night. Figure 4.1 shows part of the EDL for the small solicitation.

\begin{tabular}{|c|c|c|c|c|c|}
\hline Cage & Drawing Number & $\underline{\text { Rev }}$ & NR Sheets & Furn Code & Noun \\
\hline 81755 & $12 W 7646$ & B & 0000 & $\mathbf{S}$ & SUPPORT \\
\hline 81755 & LM12W7646 & D & 0000 & $\mathbf{S}$ & LIST OF MATERIAL \\
\hline 81755 & $12 Z 001$ & $J$ & 0000 & $S$ & INTERPRETATION DRAWING \\
\hline 81755 & $89 \mathrm{C} 0610$ & - & 0000 & $\mathbf{S}$ & ECO \\
\hline 81755 & LM12Z001 & B & 0000 & $\mathbf{S}$ & LIST OF MATERLAL \\
\hline
\end{tabular}

Figure 4.1 Partial engineering data list.

The first, third, and fourth drawings listed in Figure 4.1 were identified on EDCARS as 12W7646, 12Z001, and $89 \mathrm{C} 0610$ respectively. However, for these drawings, EDCARS delivered CALS compliant files with file names d001r018, d001r022, and d001r023, respectively. Since these CALS compliant file 
names are not used anywhere in the solicitation to identify the drawings, verification that the appropriate drawings had been delivered by EDCARS required some investigation. (See section 5.1.2.)

\subsubsection{CALS Raster Image Data Evaluation}

Digital images from the three data sets were assembled and electronically transferred to LLNL for evaluation. This subset of the digital data prepared by EDCARS was evaluated to ensure that each file constituted a valid CALS file, as well as to note the legibility, quality, and quantity of the data. The primary focus of this analysis was to determine the usefulness of these digital images as representative engineering information. Evaluation of several files using the AFCTN tool DecompG4 indicated that the CCITT Group-4 compression algorithm had been appropriately applied. SM-ALC also provided LLNL with a reference deck of aperture cards of the complete technical data for each solicitation.

\subsubsection{Compliance with MIL-STD-1840}

Before test execution, the test team elected to not use MIL-STD-1840 declaration files because 1) the X12 EDI standard was assumed to provide the logical links between all procurement and technical data files, and 2) there were no routine procedures to export CALS data from SM-ALC EDCARS. Not having declaration files made organizing quantities of digital data, even for image analysis, difficult.

All image file names from the small and medium solicitations, and some from the large one, began with the same literal character string (d001), implying that they belonged to the same CALS data set. Other large solicitation image file names started with d002, which implies that the large solicitation is comprised of two separate CALS data sets. A more thoughtful application of MIL-STD-1840 file naming conventions and the inclusion of appropriate declaration files would have the file names of each solicitation start with a unique d00n string, thereby enhancing identification of the three data sets.

Also, the numbering sequence of the files in each solicitation was not contiguous, as required by MILSTD-1840. This made ascertaining the completeness of each data set difficult. In several instances, the identical filename was used in more than one data set; MIL-STD-1840 alone does not prevent such an occurrence, but a well thought-out contractual agreement between buyer and contractor should avoid it.

All CALS MIL-STD-1840A datafile headers were properly structured with appropriate ASCII header records. Attributes required to display the image were present and applicable. All images were correctly identified in the CALS header as MIL-R-28002A Type-I images.

\subsubsection{Observations and Comments}

- Hierarchically organizing the files by assembly, sub-assembly, and detail information could support partial delivery or data access, letting contractors access only the level or amount of data needed.

- The two ALC computer systems that host the procurement process, and the archival and delivery of engineering data are only procedurally related. Although both systems are accessible through a LAN, the processes to share information between them are currently manual.

- Any solicitation available in both physical (aperture card) and digital (CALS) forms must be validated to ensure that both provide identical technical content.

- Synchronization and coordination of CDMS and EDCARS processes are currently somewhat problematic. It is anticipated that JEDMICS, the DoD migration system for engineering data slated to follow EDCARS, will address RFQ and technical data coordination issues in the future.

- EDCARS has only limited TCP/IP network access.

- The non-trivial amount of image data involved in the procurement process has caused some concern. Care should be taken not to overload an existing base network infrastructure to support electronic procurement, due to the large amount of image data involved. 


\subsection{Convention Meeting and Guide}

At the time of the test, DoD had not yet formulated a formal method or convention for use of the ANSI ASC X12 Specification/Technical Information (841) transaction set. The test team invited Logistics Management Institute (LMI) to help define a draft implementation convention for 841 , which would be used for the test, and which could serve as the basis for the implementation convention for 841 throughout DoD. LMI's participation in this activity was funded by the Defense Logistics Agency (DLA).

LMI facilitated a series of meetings held at SM-ALC to discuss the use of 841 , which were attended by the test team, some test participants and a few interested DoD observers. Attendees examined in detail the various sections and capabilities of 841 , and agreed on how it would be populated for use with the demonstration. This agreement led to the first DoD draft implementation convention for 841 , published by LMI in September, 1992. Based on this convention, the EDI software vendor participants wrote or modified translators to produce the X12 841 transactions that were transmitted via the VANs, and to process those same transactions received by the participating contractors.

During the course of the demonstration, the test team discovered other potentially beneficial uses of the 841 transaction set, which led to a meeting, held in January, 1993 at SM-ALC, to present these additional applications. At this meeting, which was attended by many of the same organizations that attended the first series of meetings, and by representatives of all DoD Services and DLA, support was obtained for modification of the DoD implementation convention for 841, and of the X12 841 transaction itself, to accommodate the following applications:

1. Solicitation Technical Documentation - provides for transmission of technical documentation to accompany an 840, as was done in this test. (AD - A272232)

2. Reference - permits the user to reference technical documentation that is part of an 840 without actually transmitting this data. (AD - A272109)

3. Request - allows a solicitation recipient to use 841 to request technical documentation. It can also be used as a follow-up when a response to a request has not been received. (AD - A272108)

4. Response - used to transmit technical documentation in response to a request. Also, to provide limited status to the originator of a follow-up request. Can indicate that requested data may be sent by means other than in the BIN segment of 841. (AD - A272231)

5. Furnish - can transmit technical documentation which is not necessarily associated within an 840. E.g. contractor transmits drawings associated with an engineering change proposal or bid; DoD transmits technical documentation to a data repository. (AD - A272107)

At this same meeting, improvements of the capability of the X12 840 transaction set were also discussed and were subsequently pursued. The proposed modifications to X12 841 have been successfully proposed to the appropriate X12 organization. The resulting five applications of the DoD implementation convention for 841 were published by LMI and released in August 1993. Copies of the Draft DoD Implementation Convention for X12 841 can be obtained from the Defense Technical Information Center at (703)274-6871, or the National Technical Information Service at (703)487-4650. Reference the appropriate accession number (AD-A272nnn) noted above. 


\section{Collecting, Merging, and Transmitting Solicitation Data}

\subsection{Transferring Engineering Data from EDCARS to Site IGP}

For this demonstration, EDCARS generated CALS raster image files on 9-track tape, rather than aperture cards. These image files were read from the tape on to the SM-ALC site IGP. Using File Transfer Protocol (FTP), files were successfully transferred between EDCARS and the site IGP. However, this process was not used throughout the test because the 9-track tape was already on hand, and was a more convenient medium for accessing the test files. The network file transfers were performed only to prove a capability, not to establish a primary path.

\subsubsection{Site IGP}

The Site Intelligent Gateway Processor (IGP) is computer hardware and software designed to serve as the single resource needed to integrate local computers and networks to allow communications with other enterprises. It supplements local system capabilities by providing the additional capabilities needed for electronic commerce. The site IGP may interface to local systems, users, or both.

\subsubsection{Accepting Data at Site IGP}

A tape utility was used that read the tape generated by EDCARS and checked it for tape formatting errors and readability. This utility also reported the total number of files contained on the tape, which was used to automatically create a script that would read in each file, placing the files in a staging directory on the site IGP. Once the files were read, they were associated with the drawings listed on the EDL. The problems encountered during association are illustrated by examining three files from the small solicitation, named d001r018, d001r022, and d001r023.

Figure 5.1 shows the srcdocid: field of the CALS headers of these three drawing files.

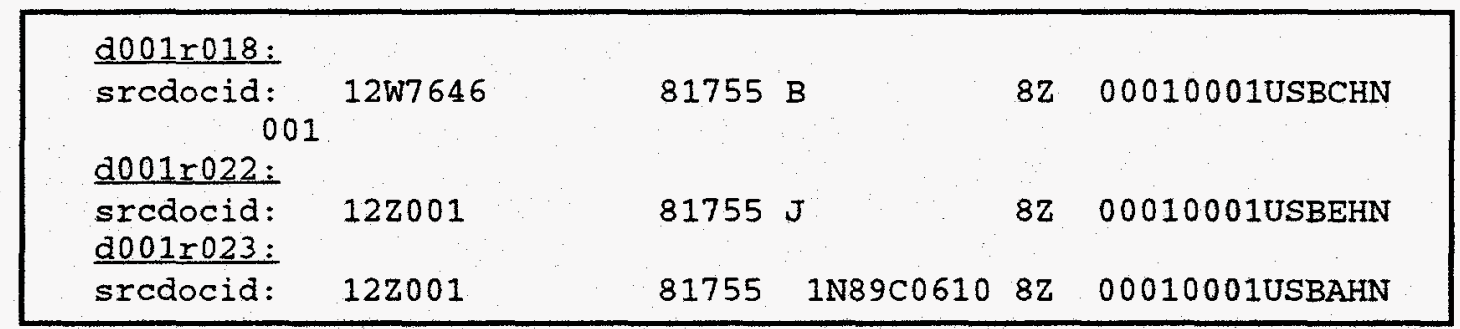

Figure 5.1 Listing of CALS MIL-STD-1840A data file header records for 3 bid set image files.

File d001r018 was quickly associated with drawing 12 W7646 on the EDL, as the drawing number was the first character string encountered in the srcdocid: field of the CALS header. However, uniquely identifying the drawing number is tougher for the other two files, because the srcdocid: field in both files begins with $12 Z 001$. A procedure more complicated than that used to identify the first file is required for the general case. For this test, the entire srcdocid: field of each file was compared with the drawing numbers on the EDL. Then, using scripts created by St. Paul Software, the file was placed into the appropriate staging directory on the site IGP, one directory for each solicitation. One of these scripts directed Datatran, the EDI translator, to assemble 841 transactions from the files in these directories.

To avoid the increased complexity of requiring a single 840 (RFQ) to be associated with multiple 841 s (see Section 5.3.1), the test team elected to place all drawing files for each solicitation into a single 841 . 
Figure 5.2 shows a listing of one of the $841 \mathrm{~s}$ used during this test, as generated by Datatran. The actual binary portion of this 841 has been removed for brevity and clarity.

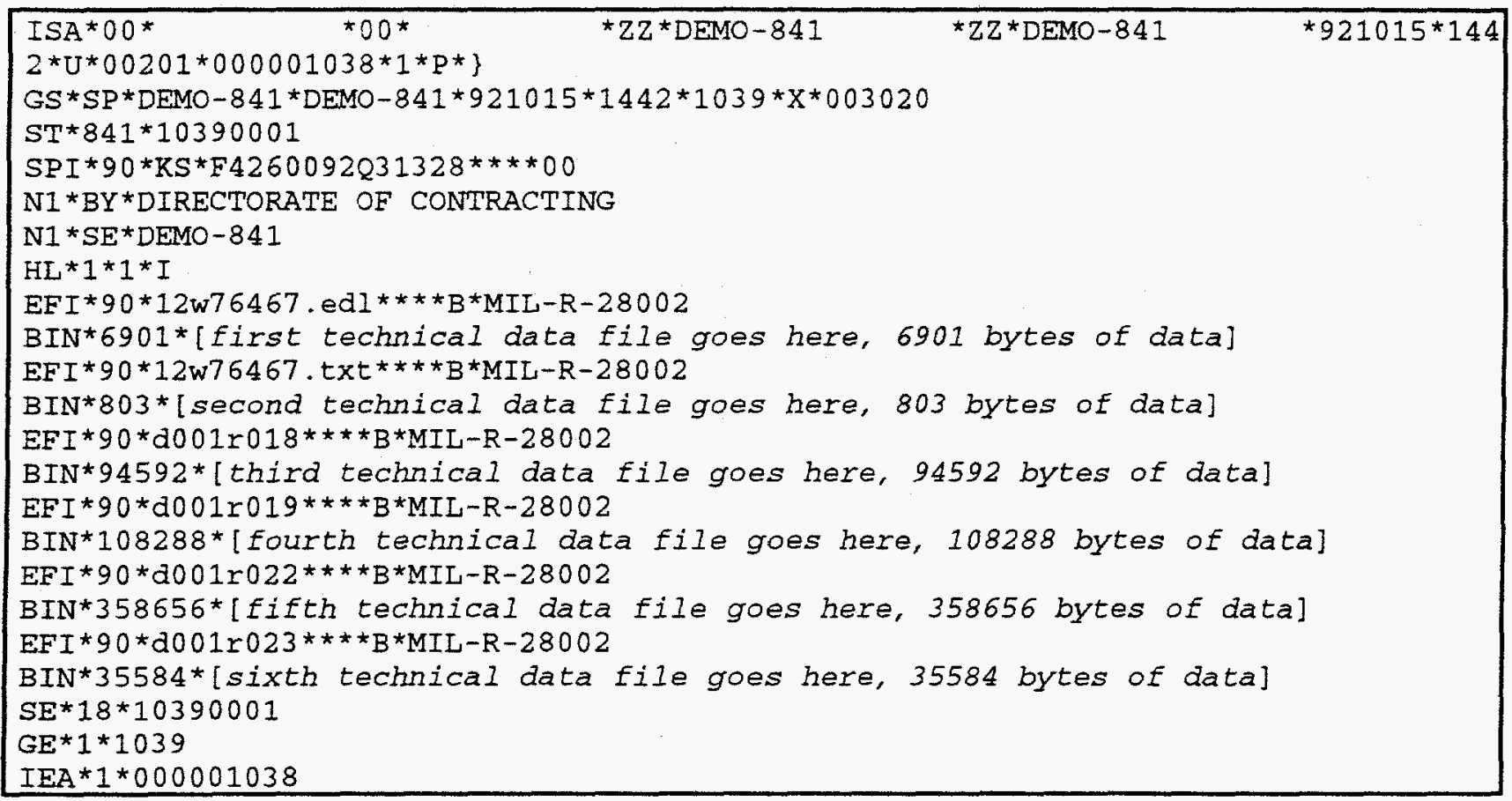

\section{Figure 5.2 Example X12 841 transaction.}

\subsubsection{Checking Data on Site IGP}

The images could not be checked on the site IGP as it had no display capability. The images were checked by transferring them (via FTP) to a PC with display capability. On the PC, the technical data images were displayed using HiJaak for Windows.

\subsubsection{Suggestions for Implementation}

Depending on the data size and the procurement requirements, the technical data set should be delivered to the EDI processor via either magnetic tape or network. Moving and staging CALS data for use in electronic RFQs must be reconciled with the availability of network and storage resources.

Tape transfers have many advantages over networks, such as low cost of storage versus disk, reduced traffic on the network, and for EDCARS, existence of 9-track tape output mechanisms; network-based mechanisms currently do not exist. Due to the long delay between availability and actual use of solicitation technical data, system storage capacity may be a serious issue, and tape storage may be preferred. However, progressive system installations are rapidly moving away from 9-track tape for storage or transfer in favor of magnetic or optical disk and network solutions.

While network transfer solutions may be more elegant, for on-base data interchange, the potentially large increase in network traffic may exceed current capacity. Application of both tape and network technology, each where it is most appropriate, should be considered. Redundant processes could utilize both technologies for backup procedures. 


\subsection{Transferring RFQ Data to Site IGP}

The electronic RFQs were transferred from ACPS to the site IGP by an automated FTP process. This FTP process was executed repeatedly, with each execution deemed successful. The EDLs were transferred from the IBM 3090 to a PC using Kermit. The EDLs were then written to a diskette and transferred to another PC, then uploaded via network connection to the site IGP.

\subsubsection{Observations and Comments}

The EDLs were circuitously routed (IBM 3090 to PC to diskette to PC to site IGP) rather than transferred directly due to complex organizational permissions and procedures beyond the scope of this demonstration. These base organizational issues would be addressed and resolved in a production environment.

\subsubsection{Suggestions for Improvement}

In a production system, the information from ACPS should be automatically transmitted to the site IGP via direct electronic connection.

\subsection{Merging Technical (CALS) and Business (RFQ) Data}

In the paper-based solicitation environment, an RFQ and its technical data are associated due to their co-location in the same physical envelope. In an electronic process, the same type of relationship must somehow be maintained without the use of the physical envelope.

Digitally associating the files which contained the RFQ information (840) with the files which contained the technical information (841) involved creating two unique identifiers (pointers) for each solicitation: one for the RFQ data, and one for the technical data. The pointer to the RFQ data was placed into each 841 that contained the corresponding technical data, and vice versa, before all the files of a given solicitation were submitted to the translation process. During the test there was no available automated mechanism for mapping ACPS RFQ information into an 840 which acceptably referenced any pertinent 841(s). Therefore the 'translation' of the 840 was a process of editing, by hand, a file that closely approximated a valid 840 , and manually adding the necessary reference to 841 .

\subsubsection{Observations and Comments}

The pointers between 840 and 841 must make unique identification of a given transaction possible. In the case of more than one 841 being associated with a given 840 , it is important that each 841 point to the appropriate 840 and that each 841 have the capability of being identified as " $m$ of $n$ " (for instance, 2 of 5 ), where ' $m$ ' is the current sequence number and ' $n$ ' is the total number in the sequence. Each 841's reference to the 840 will identify the 841 as a member of a particular solicitation, and the " $m$ of $n$ " identification will facilitate determination of the completeness of the solicitation.

\subsection{Transmitting Solicitations to Contractors}

An existing, standard phone line was used to connect to the VANs. The site IGP directly used this line and UNIX to UNIX copy (UUCP) networking for communication with the AT\&T VAN. For communication with the Advantis VAN, the site IGP used Ethernet to access a PC that was on this phone line, which used IBM's Expedite software for VAN access. In both cases, multiple modems, shown in Table 1.1, were used. 


\subsubsection{Modem Capabilities}

The modems were used at speeds from 1200 to 9600 baud to verify accessibility of the two VANs at different rates. Both VANs exhibited adequate performance at all speeds tested. 9600 baud was used for actual transmission of the solicitation data. SM-ALC used a toll-free number to access the AT\&T VAN, and used both a toll-free number ( 2400 baud) and a long distance number ( 9600 baud) to access Advantis.

\subsubsection{Two VANs Used}

The two VANs used for the test were the AT\&T Global Messaging Service (GMS) and the Advantis Information Network. This selection was based first upon each network being able to satisfactorily demonstrate the exchange of binary technical data in the form of X12 841 transaction set(s), and second upon the network volunteering to participate. The use of two VANs permitted the same data to be routed over two separate and distinct telecommunication paths to different destinations. Test statistics indicated that both VANs demonstrated satisfactory delivery and performance.

These two VANs were also selected because they use two different backbone transport technologies. AT\&T uses X.400 technology, while Advantis uses ISO 80223 technology. This allowed the test team to identify any appreciable differences, and any characteristics that were more or less favorable in an operational electronic contracting test environment. Both technologies performed as expected and no differences were noted.

\subsubsection{Observations and Comments}

The data transmission technologies used were very reliable and performed very close to the transfer rates expected in simple calculations. Neither the UUCP logs nor the Expedite reports showed any unaccounted failures, slow downs, or other anomalies.

The test team encountered difficulty transmitting the large solicitation end-to-end. This solicitation, which was over 8 Mbytes in size, was successfully moved from SM-ALC's site IGP to the Advantis VAN, and to a contractor participant's mailbox. However, that contractor was unable, due to unavailability of higher speed local Advantis telephone access, to access his mailbox at speeds faster than 2400 baud. $\mathrm{He}$ attempted to download the large solicitation for over 24 consecutive hours before finally aborting the process, and was unable to ultimately identify the content of this transmission.

Although SM-ALC tried several times to transmit the large solicitation using the AT\&T VAN, these transmissions never appeared in the recipients' mailboxes. The AT\&T VAN had a 2 Mbyte message size limit, which could be modified by AT\&T. AT\&T apparently attempted to lift this size limit to accommodate SM-ALC's several transmission attempts, but the success of these transmissions was never verified, and the cause of the difficulty was never determined.

\subsubsection{Projected Cost of VAN Use}

As a typical example, in January 1994, the cost to transfer a kilobyte (Kbyte) of data was approximately five cents, which equates to approximately $\$ 50$ per megabyte. Therefore, a typical "business form" of 4 Kbytes can be transferred in seconds for 20 cents. A 300 Kbyte message of technical data can be transferred in minutes for approximately $\$ 15$, which is about the same cost as an overnight express package, but with EDI and a VAN, the data is loaded at the destination one day sooner. 


\section{Observations on Data Receipt}

This section discusses the contractors' receipt of the electronically delivered solicitations. This section's scope includes using EDI software to access the VAN, download data from the VAN, and navigate the received messages on the user's PC. Selected comments from the contractor participants are included. One contractor remarked, "EDI is the best thing to happen to Government contracting."

\subsection{Background}

The eight SM-ALC contractor participants each used his or her own IBM Personal Computer or IBMcompatible computer systems to receive and process the data. Supply Tech, Inc. provided STX EDI software to download transactions from the VAN to each receiver's local system.

\subsubsection{Necessary Hardware and Software Capabilities for Data Receipt}

\subsubsection{Control Over Download and Message Selection}

The user should be able to view a summary description of the messages in his mailbox, then initiate a download command to retrieve all or some of the available messages. A large technical document package of more than a few megabytes could take several hours to download, unlike a typical business transaction which takes only seconds or minutes. The ability to view a summary of the available messages, including the amount of data, would 1) allow the user to determine when best to download the messages, such as immediately or after working hours and 2) give the user control over the sequence of message retrieval, and allow him or her to optimize procedures for processing incoming messages.

\subsubsection{Operate with a Variety of Input Formats, Including Binary}

Because this test transferred binary encoded CALS raster image files, along with ASCII RFQ information, VANs and EDI software included in the test necessarily supported the transfer of ASCII encoded messages and mixed-mode (ASCII and binary) encoded messages. Historically, EDI messages were small, and were exclusively ASCII. Some VANs have not modernized their networks to handle binary files as provided for in some newer X12 transactions. Some others cannot handle a mix of binary and ASCII. Only a few VANs, generally those that are X.400 or ISO 80223 backbone based networks, can handle all these transmission types. Increased CALS and other binary data traffic, and competitive business pressures from those VANs who are capable, may accelerate widespread support of binary and mixed capability.

\subsubsection{Mailbox Concepts}

The mailbox concept allows a user to be identified by an address on the VAN. Having a mailbox on a VAN is like having a Post Office Box at the Post Office. Just as one must physically go to the Post Office to pick up one's mail from the P. O. Box, in order to retrieve mail from the VAN, one must access his VAN mailbox to retrieve messages. The VAN mailbox is controlled by the VAN and remote to the user.

VANs can operate in many ways. Some VANs are basic "store-and-forward," where the data to be sent is kept in the sender's mailbox until the VAN services it. With store-and-forward, or "batch" processing, an outgoing transaction can be delayed by minutes or hours before it is moved to the destination mailbox. Other VANs, such as those operating on X.400 backbones, behave as "virtual forward-and-store." This means that an EDI transaction is forwarded to the destination immediately after it is loaded into the sender's mailbox. This is significant to a user if the delivery of the message is time critical. 


\subsubsection{Software to Download and Translate EDI Messages}

The STX EDI software provided access to the user's VAN mailbox, via a modem, so he or she could retrieve the mailbox contents. It automatically downloaded messages to the user's local system, and provided some cataloging and organization of the incoming transactions. And, it separated each incoming 841 transaction into its constituent parts: one file containing the non-binary portion, and a separate file for each binary segment in the 841 .

\subsection{Observations and Comments}

\subsubsection{No Control Over Download or Message Selection}

The VAN user had no control over the downloading of messages from his mailbox. It was unclear whether this shortcoming was a function of the VAN or of the EDI software. When the user accessed his mailbox, the EDI software would immediately and automatically download all unread messages in the mailbox, preventing the user from just "looking" in the mailbox for new messages. Lacking such control during the test, the user would be "surprised" to either retrieve or not retrieve any new messages.

Closely related to the inability to determine the "fullness" of the mailbox is the inability to ascertain the contents of the mailbox. During the test, the user would have to wait for the download process to complete, perhaps several hours, before he could check his local system to see what he received. The user should be able to control the download and retrieval process, and select the messages to retrieve. Two contractor participants expressed the desire to know message sizes (in bytes) and approximate download times for each message before the download process started, so they could ensure the availability of appropriate disk space and computer resources.

[Editor's note: The VANs used in this test have indicated that they now provide a new "selective download" capability which provides all of the functional capabilities discussed in Section 6.2.1.]

\subsubsection{Automatic Removal of Messages from Mailbox}

With Advantis, messages appeared to remain in the mailbox indefinitely. Once a message was retrieved by the user, it was marked as retrieved, so that future mailbox accesses would not retrieve it again. With AT\&T GMS, a message would be held in the mailbox for five days, after which the message would be deleted, whether it had been retrieved or not. If the user did not access the mailbox during that fiveday period, the message would be lost, and it would have to be re-sent to the recipient. This happened frequently during the test, when a message was sent on a Friday, and for various reasons the recipient would not access his mailbox until after the message was removed. As with Advantis, once a message was retrieved, it would be marked as retrieved to prevent re-retrieval. It should be noted that in a production environment, several-day delays in processing incoming messages are a-typical.

At least one test participant said he would like to be able to delete mailbox messages himself.

\subsubsection{Business Computer Tied Up for Long Periods}

At 9600 baud, downloading large amounts of data was considered too slow for production. Most participants owned only one PC, which would be taken over by the EDI retrieval process, sometimes for hours. This rendered the system unusable for the other functions it normally performed during the business day, significantly impacting and sometimes paralyzing the business' normal operations. Those who used Advantis were limited to unacceptable transmission speeds of 2400 baud. As the recipients became more familiar with the download process, most elected to wait until the end of the day to check their mailboxes. One contractor participant commented, " $[\mathrm{I}]$ do not believe small business can compete 
with EDI 841 transactions due to cost of time required." Another noted that for their particular situation, they would purchase a PC dedicated to EDI for production EDI use.

\subsubsection{Download Times and Other Factors}

Recipients observed a wide range of download times, due to several factors, such as their system configuration, the baud rate of the transmission, and the integrity of the telephone connection. Participants indicate that the excessive download times are a big load on their limited computer resources. Some note that a 386 is inadequate for EDI 841 processing, and that a higher-end system is required, with large disk capacity. Another noted that having only 10 Mbytes free on the hard disk prevented successful retrieval of messages. Another experienced download problems when the phone connection was repeatedly severed unexpectedly.

Some quantitative comments on download performance include:

- $\quad$ "...at 2400 baud, download of [3] files required 2 hours."

- “...downloaded files successfully in 2.5 hours." [21 files at 9600 baud].

- transfer times very quick ( 60 seconds).

- "Transmission...was in its 24 th hour before terminating communication session." After 18 hours 5 Mbytes had been received, after 23 hours, 7 Mbytes. [ 8.6 Mbyte transmission at 2400 baud to a 386 processor].

- 4 Mbytes took 2 hours at 9600 baud.

- 1 hour to download 0.5 Mbytes at 2400 baud -- "too long."

\subsubsection{Access to Faster Transmission Rates}

Surprisingly, those users who had an Advantis mailbox, who were all located in the greater Los Angeles area, were required to access their mailboxes at a speed no faster than 2400 baud, unless they made a long distance phone call. Due to the large solicitations and long transmission times, the cost of such a long distance phone call, even at 9600 baud, was prohibitive. This possible limitation in service availability should influence a potential user's selection of a VAN.

\subsubsection{Organization of Files on Local System}

STX placed all retrieved files into a single directory, ensuring that each file had a unique filename. With all files of all received messages in the same directory, it was difficult for the user to tell which files belonged to each message. For each 841 transaction, STX created a summary file of the non-binary portion, and a separate file for each included binary segment. For the small solicitation, this generated six files, and for the medium solicitation, ten files. The binary image files were given sequentially ordered filenames, i.e. BIN00001.DAT, BIN00002.DAT, etc. While STX recorded the names of the binary files in the 841 summary files, the user found it necessary to print out the summary files, then reconcile which binary files went with each solicitation, a somewhat tedious process. Perhaps placing each 841 transaction in its own uniquely identified directory would be more helpful. The software could use the filenames that are in the transaction itself rather than generating new filenames. This would save the user from mentally translating from the original filename to a new one. Most contractor participants found the sequential image filenames meaningless, and would prefer more descriptive filenames, such as a drawing number, list of materials number, or engineering data list number.

\subsubsection{Telephone Lines}

Most small business participants had only one incoming phone line, on which they relied for all external communication. During download, this line would be taken over by the modem, blocking all other 
external communication. Small businesses contemplating EDI should strongly consider adding a second phone line dedicated to data transmission. The type of telephone system used in the business can also cause concern. Some allow a single incoming line, which may be "split" to allow multiple simultaneous telephone conversations. One such system, Merlin, requires a special adapter to allow uninterrupted data communication. The cost of this adapter was $\$ 250$ (in 1992).

\subsection{Tips for VAN Selection}

The costs of using third party VAN services depend on three variables:

1. The amount of actual use. Almost all VANs charge by the amount of data or number of bytes actually transferred. A few VANs charge by the length, in minutes, of connect time.

2. The quality, performance, capacity, throughput, and functionality of the services offered, including some billable optional features which can vary the cost considerably.

3. The dynamics of the competitive commercial marketplace, plus the decreasing cost of technology, VAN implementation, and operations.

All these factors affect potential VAN costs. Interestingly, high performance does not always imply high cost. Also, guaranteed delivery within a specified time period and during prime time may not cost more.

A contractor who is considering subscribing to a VAN, and who will be sending or receiving technical information, should ensure that the VAN is capable of transferring binary files with full integrity and without data alteration. Second, consider a VAN that will deliver the data within a few minutes and at no additional cost over one which may wait, perhaps until overnight, for batch processing. Third, compare VAN fee schedules, which differ for each EDI VAN service provider. In general, the more items a VAN charges for (e.g., number of bytes, reports, connect fees, time of day, total number of messages, etc.), the lower the charge for each item, and vice versa. Most VANs charge a minimum monthly fee, which can vary from $\$ 3$ on one VAN to $\$ 150$ on another. Most VANs also charge for the amount of data transferred, from 50 cents for 10 Kbytes (about 8 pages of text) to many times this amount. Some VANs also have a per message and/or per connect charge. Even though the choices and decisions appear complex, a contractor can change VANs as easily as switching to a new long distance telephone company, so a VAN selection decision need not be seen as irreversible.

\subsection{Additional Useful Capabilities}

A few additional capabilities of the EDI translator software, such as "unattended operations" and "overlay generation," can be beneficial in an operational environment.

Unattended operations allows the EDI software to operate unattended, so that incoming messages can be downloaded directly to the recipient immediately upon arrival in the mailbox. This can save valuable time in bidding and other normal business processes. Also, outbound messages can be formatted, packed, and issued nearly automatically. Without this option, numerous time-consuming (and sometimes error prone) data entry functions may be required.

Overlay generation enables the user to generate EDI message templates, or "overlays," for additional EDI transactions as the variety of EDI messages used expands. A new EDI user typically uses six or less of the over $\mathbf{2 5 0}$ messages currently available. Over the years, he could easily expand his EDI messaging capability if he has the overlay generation feature. Alternatively, the user must perhaps pay his EDI translator vendor to add new messages to the user's installation. Overlay generation is financially beneficial to larger EDI operations and businesses with easy access to knowledgeable software personnel. For a smaller business without such resources, it may be more cost effective to have the translator software vendor provide an overlay generation service. Unlike the unattended operations option, overlay generation can be added after initial installation, with no impact on the existing system. 


\section{Observations on Data Usability}

This section discusses the contractor participants' attempts to view and process the CALS images. This section's scope includes manipulation of the received data files, displaying and printing the images, and general preparation of the received items for analysis and bidding.

The CALS strategy asserts that a digital image environment, in the aggregate, is more cost effective than the equivalent paper or microfilm methods. Certainly, the processes associated with generation, filing, and retrieval of digital documents have advantages, such as fewer lost documents, improved accountability, reduced material costs, and greater accuracy of copies.

\subsection{Background}

Inset Systems Inc. loaned the eight SM-ALC contractor participants HiJaak decompression and display software, which was capable of processing CALS MIL-R-28002 Raster Type-I compressed binary files. The software was compatible with the computer systems used to download the transactions from the VANs. In addition to HiJaak, Myriad, produced by Informative Graphics Inc., was used by the AFCTN and SM-ALC during the test.

\subsubsection{Necessary Hardware and Software Capabilities for Data Display}

The user should have access to digital capabilities which parallel the optical viewing process. The technical solution should be low cost, readily available, reliable, flexible, expandable, and easily tailored to meet a business' current and future needs. The hardware must be capable of supporting image display requirements, and the software must support image decompression and display.

A system used to receive EDCARS source data should provide 8 Mbytes of bit-map storage to display the largest allowable EDCARS image. Storage may be provided as RAM or as disk space. The speed and number of drawings required will directly affect the hardware and software requirements. Optimal software setup, during and after installation, is also very important.

\subsubsection{Ability to Process CALS Files}

The CALS raster image files used in this demonstration consist of two types of data: attribute and content. The procedural and image attributes are supplied at the beginning of the file, in an ASCII header. To successfully decompress and display CAIS raster images, an image processing tool must parse the ASCII header, read the scan line length record parameters in the CALS header, and convert them to binary values for use in the decompression process. Decompression of the encoded binary image into a bitonal bit-map is required before any other display function can be undertaken.

\subsubsection{Other Factors}

1. Intuitive Operation - An intuitive viewing capability is highly desirable. The user should be free to concentrate on viewing the image rather than on manipulating the display tool. Although a display tool may have a wide range of functions, if it is not intuitive, the display process may overwhelm the user.

2. Ability to Rotate and Zoom - Display software should provide adequate rotation and zoom capability, at acceptable speeds, when working against files in formats native to the particular display packages.

3. Printing - The CALS image display system should be able to produce paper hardcopy of the image. 


\subsubsection{Details About the Software Used}

Some software packages not capable of processing CALS files require an image conversion process before the image can be displayed. The display software used was capable of converting and displaying CALS MIL-R-28002 Type-I raster images. It was also capable of magnifying and reducing the digital images through a "zoom" function, which would shrink the entire image down to fit in the display area, or enlarge the smallest artifact to fill the computer screen.

\subsection{Observations}

From the user's perspective, viewing the images proved to be frustrating and time-consuming. The several factors involved are outlined in the following sections. In addition to the quality and accessibility of the images, observations on the usability and completeness of the data content are included.

\subsubsection{Renaming Files}

Being unaware of one of HiJaak's setup options, which allows the user to specify any or no file extension to be used to identify CALS raster files, the raster file recipients manually changed the file extension of each raster file received to .CAL. . CAL is the default file extension used by HiJaak to recognize input files as CALS files. The test team became aware of this setup option, which would have obviated manual renaming, after the testing was concluded.

\subsubsection{Decompression of CALS Files}

One of HiJaak's primary capabilities is conversion of image files from one type to another. HiJaak can convert a CALS raster file into a more familiar file format, such as PCX, which can then be processed by another display program, such as Paintbrush for Windows. Many of the test participants were too unfamiliar with alternative file formats and other specialized features of their computer systems to try this. They instead used HiJaak to display and print the images, as well as decompress them.

\subsubsection{Observations on Performance}

The test team can make no definitive statements on performance, since no benchmark performance tests were used in this analysis, hampering the evaluation of the timing tests. A range of performance results can be derived from available image data display products. Users are encouraged to investigate the functionality and performance required for their individual applications. Performance figures shown here, taken in late ' 92 and early ' 93 , may not directly correlate to the performance of products available today. Many prominent CALS product vendors, such as Inset Systems, take steps to respond to the highly competitive market of short life-cycle PC software, and have made dramatic performance improvements.

The decompression/display times provided by all participants (LLNL, SM-ALC, and the contractors) vary widely, from 1 to 4 minutes using a 486/25DX processor, to 10 and 15 minutes on a $386 / 16 \mathrm{MHz}$ CPU. The extremes stem from differences in system configurations, installation parameters, hardware speeds, software versions, memory access speeds, and buffer sizes. An optimum configuration based on a more recent version of either HiJaak or Myriad should provide decompression times between 1:20 and 0:15 or faster. Users converting from CALS Type-I raster format to an intermediate format (such as PCX) for displaying, printing, and editing, will experience longer decompression times.

In a number of cases, the contractor participants indicated that their decompression performance was too slow to be useful in a production environment. 


\subsubsection{Performance Statistics}

Timing tests on SM-ALC and LLNL platforms reflect the performance differences in varying hardware and software configurations. The LLNL AFCTN test bed and SM-ALC both used PC configurations that decompressed and displayed an image in the 0:15 to 1:45 range. LLNL's platform was a $25 \mathrm{MHz}$ IBM PS/2 Model 60 with 2 Mbytes of memory and a 33 Mbyte hard disk. SM-ALC's platforms ranged from a $25 \mathrm{MHz} 386$ with 7 Mbytes of memory to a $50 \mathrm{MHz} 486$ with 10 Mbytes of memory.

LLNL conducted a stop-watch test on four images. Each image was decompressed twice on the same system, once with the source files located on floppy disk, and once with them on the system hard disk. Decompression performance variations showed that decompression from the hard disk completed $15 \%$ to $19 \%$ faster than decompression from the floppy.

\subsubsection{Analysis of Decompressed Files}

Two of the CALS raster image files used in the test were analyzed to demonstrate the superior space efficiency of the CALS raster compression algorithm to the popular DOS image file type PCX. Results show that the PCX compression algorithm yields image file sizes that are roughly 4.5 to 6 times larger than CALS compressed raster images. Comparisons with other compressed raster file formats yielded results similar to those for PCX, indicating that CALS raster compression is the most effective algorithm, resulting in the smallest file sizes, thus making the most efficient use of disk space.

However, there is increased overhead associated with the CALS raster compression algorithm. When images were converted to PCX, BMP, or other types, they were usually displayed virtually immediately, whereas images in CALS raster format took 0:45 to 2:00 or more to decompress for display.

\subsubsection{Displaying, Rotation, Zooming}

Contractor participants who displayed the images on their computers found that the quality and clarity of the images far surpassed that of the same images on aperture cards. One contractor described the images as "surprisingly high quality, superb." Another described them as very readable, sharp.

HiJaak for Windows (v. 1.0) was successfully used to display all files on a variety of machines. Converting CALS files to other displayable or printable formats was also successful on all LLNL and SM-ALC machines. Once the images were decompressed, manipulations such as pan, zoom, and rotate were virtually instantaneous. However, the test team's perception of application performance were based on familiarity with the technology, and may perhaps differ from that of those less familiar.

Those contractors who used HiJaak experienced very slow performance when attempting to display the CALS raster images. In some cases, attempts to modify the view of the image as it appeared on the screen resulted in delays of between 5 and 10 minutes; sometimes the system would hang up or crash. One contractor noted that when manipulating a rather small 50-100 Kbyte image, any interaction that resulted in an update of the display led to a 2 minute wait. Considering a production environment, where hundreds of images could be received in a day, these speeds are unacceptable. However, the performance improvements made since the time of this test should lead to a more robust production environment. One contractor suggested that a " 55 or $66 \mathrm{MHz} 32$ bit bus system with a 32 bit video card" might be a good system configuration for image manipulation.

HiJaak can zoom both in and out on any graphic. As delivered, HiJaak's initial zoom setting was such that the image would be enlarged to display only an unrecognizable small area of the data. This was overcome by modifying HiJaak's initial display parameters. Perhaps due to system hardware limitations, contractors were not always effective at utilizing HiJaak to pan and zoom. One contractor 
participant noted that each image, when initially displayed on the screen, was rotated clockwise 90 degrees. This anomaly was corrected by applying HiJaak's rotate function.

\subsubsection{Printing}

Additional difficulties were experienced when trying to generate hardcopies of the images. Only those users with Epson-compatible dot-matrix printers could print the entire image on a single 8-1/2 $\times 11$ inch sheet of paper. These paper plots were of a fairly high resolution and were quite readable. Most users had Hewlett-Packard or other types of laser printers, which could not be successfully driven by the software. These users could only print the portion of the image that was visible on the screen.

HiJaak was not intended to print multi-page graphics; it was unable to print, for instance, an E size drawing onto four 8-1/2 $\times 11$ inch sheets. The contractor participants found this inconvenient, and Inset Systems said this could be changed in the future. Printing performance was generally found to be similar to display performance. One contractor noted that printing an 80 Kbyte image file took 5:30. Another noted that attempting to print large image files crashed the system print queue.

Some contractors successfully converted the CALS files to PCX files, and printed them using other software, such as Paintbrush for Windows. These contractors were able to print the entire image, or a portion of the image, by performing a "screen dump" of the window containing the image. These screen dumps were generally poor resolution and unreadable. The user could enlarge a portion of the full image, and using pan and print, generate multiple 8-1/2 $\times 11$ inch sub-plots, then paste them together to render the full image on paper. Such an activity can be labor intensive, tedious, time consuming, and inaccurate. Another possible solution might be to try printing on a large format plotter.

\subsubsection{Bidding from Electronic Data}

Due to the test environment, many contractors had only one computer system capable of displaying the images. Therefore, those who needed to internally distribute incoming solicitations in order to formulate a bid found sharing electronic drawings to be cumbersome, requiring all persons who normally participate in bidding to go to a common workstation, rather than work at their desks. Most of these contractor participants normally distribute or route hardcopy plots (e.g., blue prints) of the drawings so they can be evaluated for bidding. Due to the difficulties with obtaining legible, useful hardcopies of the drawings, as outlined in Section 7.2.4, distribution of reasonable paper drawings was not possible. One contractor who was unable to generate any legible hardcopies concluded that, for his company, all bidding decisions must be made by viewing the image on the computer screen. Many contractor participants concluded that without faster and more powerful display and/or plotting capability, attempting to bid using only electronic images would be more cumbersome than their current, aperture card-based processes.

About half of the contractors who returned completed checklists indicated that they could have bid from the data they received. The variation in responses is likely due to differences in internal processing at each contractor's site. It was difficult to verify the completeness of the received data, perhaps due to inconsistent delivery of a parts list or drawing list. Some of the images received were considered unnecessary for transmission, since most contractors who have been supporting SM-ALC already have most images on file from previous solicitations. One contractor indicated that he would like to be able to selectively request drawings on an as-needed basis when responding to specific solicitations. 


\section{Summary and Recommendations}

This test demonstrated that CALS and EDI can be used together to electronically deliver military RFQs that specify technical parts to small manufacturing contractors. It also identified several problem areas that need to be addressed when developing a production CALS- and EDI-based implementation. Observations, including the most significant successes of the test, along with problems and recommended solutions, are described in the following sections.

\subsection{Significant Successes}

This test used the CALS and EDI standards and commercial VANs to bring about the first electronic transfer of Air Force technical bid set data to multiple manufacturing contractors, including small businesses. One contractor, upon receiving one of the bid sets commented, "This is the best thing to happen to Government contracting."

The Implementation Conventions for the ANSI ASC X12 841 transaction set, that were developed and used for this test, were accepted by each of the DoD services.

The most impressive success observed was the ability to accomplish the entire test with a variety of COTS hardware and software.

\subsection{Observations and Recommendations}

A summary of the observations and accompanying recommendations from the test follow. The observations are all summarized from the respective chapters dealing with the subjects indicated.

\subsubsection{Engineering Data from EDCARS to the Site IGP}

Observations:

1. EDCARS does not operate from an electronic engineering data list (EDL).

2. The Ethernet connection to EDCARS was not viable for use during the test.

3. Using 9-track magnetic tapes to move the data was adequate, but required that they be hand-carried to achieve data transmission.

4. Multiple tapes were not necessary for even the largest $(<\$ 25,000)$ procurement actions.

5. The engineering drawings from EDCARS were evaluated and found to be consistent with the prescribed CALS raster format (MIL-R-28002 Type-I).

6. There was no simple, automated way to determine which CALS raster image files should be packaged in to the appropriate solicitations.

7. The "typical" bid set contained about 10 engineering drawings, requiring less than 2 megabytes of storage.

Recommendations:

1. For issues pertinent to EDCARS capability, any of the following options would be effective: a. EDCARS could be modified to operate off an electronic engineering data list. This would greatly facilitate the contracting business process.

b. An add-on front-end system could be introduced to stage data identified on an electronic EDL.

c. EDCARS could be replaced with a more modern, robust solution, e.g. JEDMICS.

2. EDCARS should deliver, along with CALS raster files, a table that shows the CALS filename associated with each solicitation aperture card or drawing, to facilitate packaging of the electronic solicitation(s). 
3. A direct electronic connection between EDCARS and the site IGP should be used to transfer engineering data. This may require software on both systems to automate two-way file transfer.

\subsubsection{Business Data from ACPS to the Site IGP}

Observations:

1. Electronic RFQs (X12 840s) had to be generated and verified by hand since, at the time of the test, there was no mechanism for converting ACPS contract information into an 840 .

2. Not all of the business data was available on ACPS; it was gathered from several sources.

3. Central contracting buyers are unaccustomed to the format and fields required in the ANSI $\mathrm{X} 12$ transaction set 840 .

4. The entire process of electronically issuing RFQs is a change for the contracting people. However, the test has indicated that automation is feasible.

Recommendations:

1. ACPS and any other computer systems containing relevant business records should be enhanced to accommodate X12 840, and should be electronically connected to the site IGP. This would facilitate electronic contracting and eliminate error-causing and time-consuming re-entry of data.

2. Such an automated system that electronically issues RFQs should be tailored to the buyer, and not require the user to have detailed knowledge of X12.

3. For the purpose of implementation, knowledgeable contracting people should be included in a team that takes a total look at redesigning the current business process.

[Editor's note: It appears that the DoD EC in Contracting Process Action Team Report addresses many such issues.]

\subsubsection{Merging 840 and 841}

Observations:

1. There was no way to specify in an 840 that 841 (s) are associated with that 840 .

2. A given solicitation consisting of multiple raster images may be larger (in terms of bytes) than a reasonable transmission size. The file organization on EDCARS does not facilitate intelligent sub-division of the solicitation images into coherent groups for transmission.

3. Since many RFQs deal with re-procurement, most qualified bidders already have most of the engineering drawings on file. Bidders only need the RFQ with an accompanying engineering data list (EDL), so they can request those drawings, if any, which have been revised since the last procurement action. There was no standard way to include an EDL in either an 840 or 841.

4. There was no obvious EDI transaction set designed for requesting specific engineering drawings.

5. The DoD Implementation Conventions for 840 and 841 did not support all test needs.

Recommendations:

1. The X12 840 Transaction Set should be modified to meet the needs of the Air Force RFQ process involving technical data. Government conventions and the ANSI standards themselves should be modified, if necessary to meet these needs.

[Editor's note: Appropriate modifications to X12 840 have been made to support this recommendation.]

2. Allow an engineering data list to be sent in an $R F Q$, in place of the complete engineering package.

3. The X12 841 should be modified to accommodate EDLs and requests for technical data. 
[Editor's note: The X12 841 transaction set, along with the DoD Implementation Conventions for 841 , have been modified according to these recommendations.]

\subsubsection{Transmission (VAN to Contractor)}

Observations:

1. Some VANs have a programmable upper limit to the size of transaction it will let pass to its customer.

2. In areas of the country where phone lines are exposed, rain, frost, wind, and lightening can affect the reliability of transmission.

3. Some VANs do not have 9600 baud service in all areas, requiring a long distance call in some locations to achieve speeds greater than 2400 baud. 2400 baud was considered too slow for doing business.

Recommendations:

1. VANs should examine their transaction size upper limits to accommodate larger technical data transfers.

2. Engineering data sets larger than the VAN's upper limit should be broken down into several smaller files (841s), and very large sets (e.g. $>5$ megabytes), should be mailed on physical media (e.g. floppies) until higher upper limits are generally available.

3. Contractors wishing to do business routinely via telecommunications lines should require the lines to be weatherproof. They should avoid transmission during lightening storms.

4. VANs should move quickly to install higher speed capability to every part of the country involved with electronic contracting for parts requiring engineering technical data.

\subsubsection{Data Receipt (Contractor)}

Observations:

1. Some engineering drawing sets were simply too large to reasonably download at 2400 or 9600 baud.

2. The receiving businesses must have a computer, a modem, and a phone line.

3. From the point of view of the small business, accessing a VAN mailbox was very easy -- it took only a phone call.

4. When accessing the VAN mail box, there was no way to control data transmission. Everything in the box was downloaded.

5. There was no apparent organization of messages (transactions) in the mail boxes, and no index.

6. There was no way to select specific transaction(s) to download.

7. The actual download can tie up the receiving computer for a very long period of time. This prohibits the use of the computer for other company business until the download is complete. In a significant percentage of cases, even the "typical" size bid set (10 drawings) took over an hour to download at 9600 baud.

8. Large messages can take hours to download. Connectivity was frequently lost during the download operation, and the process had to be restarted from the beginning. Sometimes, this required the message originator to re-send the message.

9. The largest solicitation was not successfully downloaded by any of the test participants.

Recommendations:

1. Contractors should execute data transfers at 9600 baud or faster.

2. VANs and EDI translation software vendors should provide the capability for a receiver to scan the mailbox contents (with access to information such as file sizes, creation dates, 
transmission dates, sender names, etc.), and to control the sequence in which the files are downloaded.

[Editor's note: Some VANs are addressing many of these capabilities]

3. Contractors should carefully consider the impact of download time on their business, and should be careful to not download files during peak computer usage.

4. An internal Local Area Network (LAN) can be useful. If the receiving company already has separate desktop microprocessors and/or workstations for engineering, management, manufacturing, transportation, publication, quality control, and/or administration (including order entry, project scheduling, shipping, accounts payable \& receivable), it can be useful to interconnect several of these functional areas by LAN equipment, enabling each functional area to share information.

\subsubsection{Data Usability}

Observations:

1. Upon opening the 841s with the EDI software, the data files were found to be valid CALS raster files, as sent.

2. Understanding the data content of a CALS file required viewing the image.

3. Displaying the CALS files was slow, in some cases as long as $\mathbf{1 5}$ minutes per image.

4. Only a few display software packages can read and display a CALS raster file.

5. Once a CALS file was translated into the native format of the display software, it took a long time to do routine actions such as pan.

6. Initial configuration parameters of display software can affect apparent usability of data. One display package had the initial zoom parameter set so close, the image was not visible. [Editor's note: This has since been corrected by the software vendor.]

7. Print capability and supported hardcopy devices must be evaluated against the contractor's available hardware.

8. Users not familiar with computers required a great deal of guidance and instruction.

Recommendations:

1. Ensure complete data identification information is in the CALS filename or header.

2. Testing with small contractors should continue, paying particular attention to evaluation of translation packages, display packages, and printing capability. Evaluations should be performed with the goal of publishing capabilities and results of timing tests for several software packages.

3. A user manual, with video tapes, should be available to first-time contractors by a thirdparty commercial educational business. The strategic implementation of CALS Shared Resource Centers and other outreach activities should be applied.

4. A more comprehensive evaluation of engineering document applications, imaging technology, and how that technology is most effectively applied should be done. Developing a better understanding of image applications, requirements, and advantages would help the user institute process change, and help vendors optimize the products that constitute current image technology.

\subsubsection{Recommendations to DoD Program Office}

We recommend considering adoption of the philosophy shown in Section 8.2.8, Recommendations to Future Implementors.

We recommend that the practice of making technical data electronically 'available' be implemented. One test participant suggested, after the test was concluded, that certain non-sensitive, high volume technical data, such as design aetivity specifications, could be made electronically available, e.g. through 
an EDI-accessible database, with the thought that this would provide a mechanism for both small business and DoD to ease into EDI-based contracting.

We recommend that funding be provided to execute the evaluations and education activities outlined in the preceding sections.

We recommend that EDCARS be upgraded or replaced soon to address the issues identified in 8.2.1. [Editor's note: It is anticipated that the DoD engineering data migration system, JEDMICS, will address many of these issues in the future.]

\subsubsection{Recommendations to Future Implementors}

Do not implement technology for technology's sake. For instance, in transferring the technical data from EDCARS to the site IGP, Ethernet was assumed to be the only acceptable method of transfer, yet there was a very good business case for using 9-track tape. Each analysis decision should be based upon sound business practices.

Translation, archiving, delivery networks, etc. are very costly parts of an EC/EDI implementation. We recommend a scheme where these services are separated from any one business application (e.g. contracting), in order to make each service more readily available to an entire business community. For instance, see Figure 8.1.

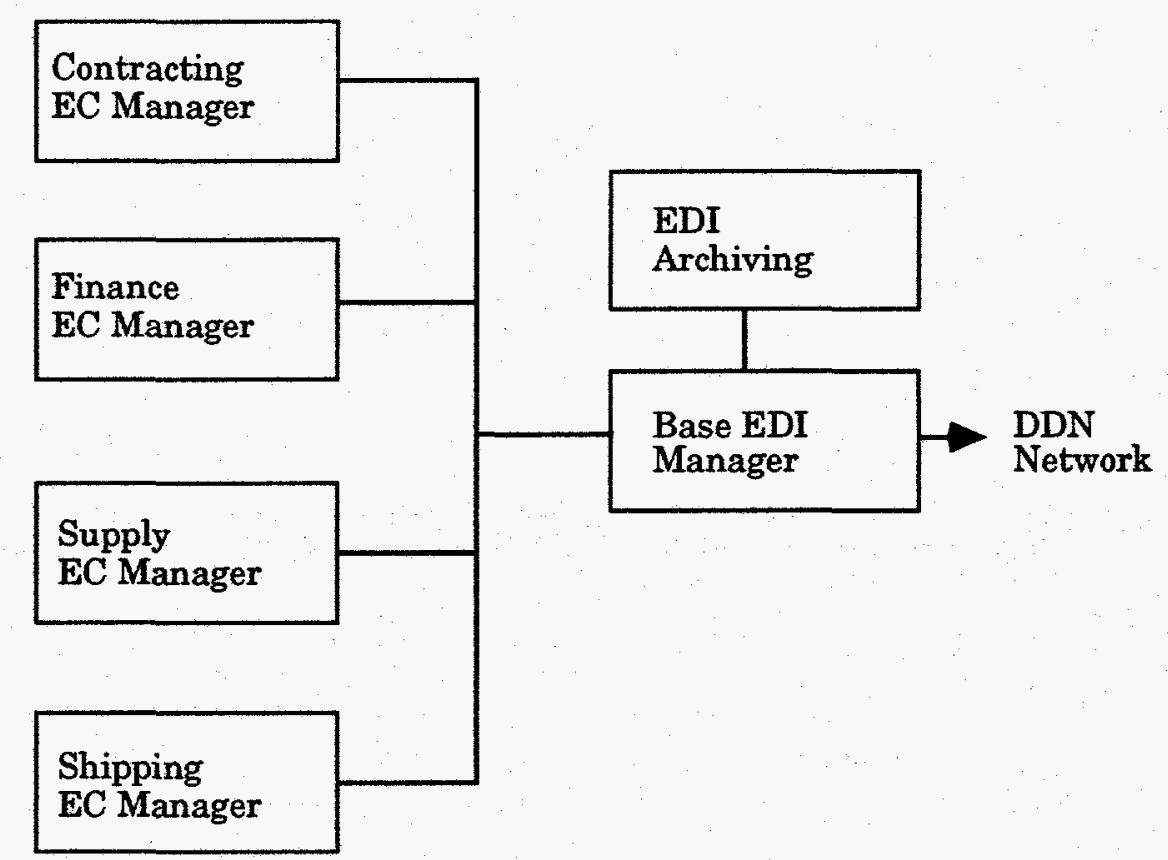

Figure 8.1 Functional block diagram of a hypothetical base-wide EDI implementation.

In this case, the different functional areas, contracting, finance, shipping, and supply have quite different existing systems and business practices. If EDI is built around any one of these, then the others may incur additional expenses in adopting EC practices, but if the functions are isolated as shown, each can be left to its own EC implementation. This approach should result in cost effective, phased implementations. 